\title{
High-resolution resistivity imaging of marine gas hydrate structures by combined inversion of CSEM towed and
} . ocean-bottom receiver data

${ }_{4}$ Eric Attias $^{1 *}$, Karen Weitemeyer ${ }^{1 \dagger}$, Sebastian Hölz ${ }^{3}$, Samer Naif ${ }^{4}$, Tim A. Minshull ${ }^{1}$, Angus I. Best ${ }^{2}$, Amir Haroon ${ }^{3}$, Marion Jegen-Kulcsar ${ }^{3}$ and Christian Berndt ${ }^{3}$

${ }^{1}$ Ocean and Earth Science, National Oceanography Centre Southampton, University of Southampton, Southampton, UK.

${ }^{2}$ National Oceanography Centre, University of Southampton Waterfront Campus, Southampton, UK.

${ }^{3}$ GEOMAR Helmholtz Centre for Ocean Research, Marine Geodynamics, Kiel, Germany.

${ }^{4}$ Lamont Doherty Earth Observatory, Columbia University, Palisades, New York, USA.

* Now at: Hawai 'i Institute of Geophysics and Planetology, School of Ocean and Earth Science and Technology, University of Hawai' $i$ at Mãnoa, Honolulu, USA. 
Attias et al., (2018), manuscript for Geophys. J. Int.

\section{SUMMARY}

We present high-resolution resistivity imaging of gas hydrate pipe-like structures, as derived from marine controlled-source electromagnetic (CSEM) inversions that combine towed and ocean-bottom electric field receiver data, acquired from the Nyegga region, offshore Norway. Two-dimensional CSEM inversions applied to the towed receiver data detected four new prominent vertical resistive features that are likely gas hydrate structures, located in proximity to a major gas hydrate pipe-like structure, known as the CNE03 pockmark. The resistivity model resulting from the CSEM data inversion resolved the CNE03 hydrate structure in high resolution, as inferred by comparison to seismically constrained inversions. Our results indicate that shallow gas hydrate vertical features can be delineated effectively by inverting both ocean-bottom and towed receiver CSEM data simultaneously. The approach applied here can be utilised to map and monitor seafloor mineralisation, freshwater reservoirs, $\mathrm{CO}_{2}$ sequestration sites and near-surface geothermal systems.

Key words: Gas and hydrate systems, CSEM, Simultaneous inversion, Tomography.

\section{INTRODUCTION}

Gas hydrate deposits are known to store vast amounts of methane, spread worldwide in marine sediments and permafrost regions, where hydrate forms and remains thermodynamically stable under high-pressure and low-temperature conditions (e.g., Kvenvolden et al. 1993; Archer 2007; Jorgenson et al. 2008; Boswell \& Collett 2011; Pinero et al. 2013; Ruppel \& Kessler 2016). Gas hydrates may contribute to climate change via methane emissions (e.g., Archer et al. 2009; Dickens 2003; Ruppel 2011; Marín-Moreno et al. 2015; Ruppel \& Kessler 2016), are possibly a viable energy resource (e.g., Sloan 2003; Collett et al. 2009; Boswell et al. 2014; Yamamoto et al. 2014), and are associated with submarine slope failures and other geohazards to deepwater exploration (e.g., Kvenvolden et al. 1993; Hovland et al. 2002; McConnell et al. 2012; Collett \& Boswell 2012; Li et al. 2016). These environmental and economic implications position gas hydrate research at the centre of broad interdisciplinary interest.

Commonly, gas hydrate structures are detected and evaluated using seismic velocity and amplitude attributes derived from methods such as semblance velocity analysis (e.g., Lee et al. 2005; Crutchley 
et al. 2015), waveform inversion (e.g., Singh et al. 1993; Korenaga et al. 1997), reflection travel-time tomography (e.g., Lodolo et al. 2002; Plaza-Faverola et al. 2010), and amplitude versus offset analysis (e.g., Hyndman \& Spence 1992; Dewangan \& Ramprasad 2007; Ojha et al. 2010). Seismic studies for gas hydrate characterisation focus on identifying bottom simulating reflectors (e.g., Shipley et al. 1979; MacKay et al. 1994) and seismic blanking zones (e.g., Wood et al. 2000; Boswell et al. 2015), which are prominent features often associated with the presence of hydrates. Although the seismic method provides structural information for inferring the presence of hydrate, it lacks the ability to assess pore fluid properties, an attribute that is essential for hydrate quantification.

Another geophysical method utilized for hydrate detection is the marine controlled-source electromagnetic (CSEM) sounding technique, which involves deep-towing an electromagnetic (EM) source dipole transmitter in conjunction with electric field receivers towed on the seafloor (Edwards 1997; Schwalenberg et al. 2005), at 50 m altitude (Constable et al. 2016; Goswami et al. 2016), or with stationary ocean-bottom receivers, which record the EM fields (e.g., Weitemeyer et al. 2006, 2011; Kai et al. 2015; Attias et al. 2016). The marine CSEM method has been frequently used for oceanic lithosphere studies (e.g., Cox 1981; Sinha et al. 1990) and hydrocarbon exploration (e.g., Ellingsrud et al. 2002; Constable 2010). CSEM data are sensitive to changes in the bulk resistivity (Edwards 2005; Constable 2010), and thus, can provide information about the pore fluid properties of sub-seafloor structures encompassed by host sediments with contrasting resistivity signatures (Harris \& MacGregor 2006; MacGregor \& Tomlinson 2014).

Recent and ongoing advances in instrumentation (e.g., Engelmark et al. 2014; McKay et al. 2015; Constable et al. 2016) and parallel numerical modelling algorithms (e.g., Galiana \& Garcia 2015; Zhang \& Key 2016; Hansen et al. 2016; Jaysaval et al. 2017) have enhanced the capabilities of the marine CSEM technique. Nonetheless, CSEM is typically considered to be a low-resolution method due to the diffusive nature of EM fields, and hence is often used in conjunction with seismic and well-log data to constrain and interpret sub-seafloor structures (e.g., Harris et al. 2009; Morten et al. 2012; MacGregor et al. 2012). High-resolution imaging derived solely from complementary CSEM datasets could significantly improve the resistivity models of new and challenging offshore targets, such as seafloor massive sulphide deposits (Mueller et al. 2016; Hölz \& Jegen 2016; Gehrmann et al. 2017), freshwater reservoirs (Evans \& Key 2016), $\mathrm{CO}_{2}$ storage sites (Park et al. 2017), and permafrost (Sherman et al. 2017). This improvement could be achieved by imaging shallow sediments more accurately, using simultaneous inversion of different CSEM datasets. Consequently, improving the overall spatial resolution of CSEM inversion models, as well as resolving deeper regions of interest with higher confidence, would thereby prevent false positives.

Here, we present 2.5-D (3-D electromagnetic source simulated in 2-D model space) CSEM in- 
Attias et al., (2018), manuscript for Geophys. J. Int.

version models of towed receiver data that show four anomalous resistors in proximity to the CNE03 pockmark in the Nyegga region, which are most likely pre-existing or emerging pipe-like gas hydrate structures. Since the CSEM data acquired from the CNE03 region are not inherently 3-D (Attias et al. 2016), the 2.5-D inversion scheme that we applied here is sufficient to describe such gas hydrate pipelike structures (e.g., Goswami et al. 2015, 2016; Attias et al. 2016). Additionally, this paper provides high-resolution resistivity imaging of a known marine gas hydrate pipe-like structure (Plaza-Faverola et al. 2010; Attias et al. 2016), obtained from CSEM inversions that combine electric field data from both towed and ocean bottom receivers.

\section{STUDY REGION}

Gas hydrates often accumulate in advective low fluid flux or diffusion-controlled geologic settings (Xu \& Ruppel 1999; Milkov \& Sassen 2002). An example of this is evident in the Nyegga region, located along the mid-Norwegian continental margin, spatially extending over $200 \mathrm{~km}^{2}$ (Bünz et al. 2003; Plaza-Faverola et al. 2012). The Nyegga region accommodates 415 pockmarks (Hustoft et al. 2010), which are crater-like bathymetric expressions of the underlying gas hydrate system (Hovland et al. 2002). Nyegga's pockmarks are characterised by chimney or pipe-like structures that are estimated to comprise $7.1 \times 10^{11} \mathrm{~m}^{3}$ of gas hydrate (Senger et al. 2010). One of Nyegga's pockmarks is the CNE03 pockmark (Fig. 1), situated in water depths of $\sim 715-730 \mathrm{~m}$ over a seabed slope of $1^{\circ}$, and underlain by an extensive gas hydrate pipe-like structure (Bünz et al. 2003; Hovland et al. 2005; Chen et al. 2011; Plaza-Faverola et al. 2010; Attias et al. 2016). Based on the classification system created by Sultan et al. (2010) and Riboulot et al. (2011, 2016), CNE03 has a Type-2 morphology, which means that the shape of this pockmark is mainly controlled by hydrate formation/dissociation within its irregular pipe-like structure that extends down to the base of the gas hydrate stability zone (BGHSZ) (e.g., Bünz et al. 2003; Plaza-Faverola et al. 2010). Hydrates within the CNE03 pipe-like structure forms in subvertical fractures and veins additionally to pore-filling, fed by free gas from a deep thermogenic source that propagates upward into the hydrate stability zone (Bünz et al. 2003; Plaza-Faverola et al. 2010, 2011). Previous studies infer that both free gas and gas hydrate coexist within CNE03 (Westbrook et al. 2008b; Plaza-Faverola et al. 2010; Attias et al. 2016).

\section{DATA ACQUISITION AND PROCESSING}

Details regarding the survey design and CSEM data acquisition used in this study are described comprehensively by Attias et al. (2016). In summary, we used a deep-towed active source (DASI) transmitter (Sinha et al. 1990), seven ocean bottom electric field receivers (OBEs) (Minshull et al. 2005), 
and a fixed-offset towed 3-axis electric field receiver named Vulcan (Constable et al. 2016) to survey the CNE03 region (Fig. 1). While Attias et al. (2016) delineated the resistivity structure of the CNE03 pipe-like structure solely using OBE data constrained by seismic information, here we provide high-resolution imaging of CNE03 by employing both the OBE and Vulcan datasets, independent of seismic constraints.

The DASI source transmitted a $1 \mathrm{~Hz}$ square wave of $81 \mathrm{~A}$, along a $100 \mathrm{~m}$ horizontal electric dipole (antenna). An altimeter and a conductivity-temperature-depth (CTD) sensor were installed to monitor DASI's absolute depth and altitude above the seafloor, whereas an ultra-short baseline (USBL) acoustic navigation system was employed to track its position. The USBL provided information on DASI's position that was later used to derive the position of Vulcan (by projecting backwards DASI's navigational information) since there was no USBL in the back of the array. In this survey, the dip of the $100 \mathrm{~m}$ antenna was not measured. Our perturbation analysis (section 5.3) suggests a $\pm 0.5^{\circ}$ of uncertainty in DASI dip. Additionally, Attias et al. (2016) performed modelling tests that showed a dip of $\pm 5^{\circ}$ had an insignificant effect on the final OBE inversion model. Therefore, because the bathymetry of the survey region is flat, we used a smoothed version of the Vulcan pitch data for DASI's dip (Fig. 2).

The data were recorded by seven OBEs and one Vulcan receiver. Each OBE was equipped with two orthogonally oriented $12 \mathrm{~m}$ long horizontal dipoles, and Vulcan was fitted with a $2 \mathrm{~m}$ long inline dipole, $1 \mathrm{~m}$ long vertical dipole, and $1 \mathrm{~m}$ long crossline dipole. Vulcan was towed $300 \mathrm{~m}$ behind DASI's antenna and flown approximately $50 \mathrm{~m}$ above the seafloor (Fig. 1), at an average speed of 1.5 knots. We collected CSEM data along four towlines at CNE03 with this array. Survey lines 1n and 2 coincide with previously acquired high-resolution seismic reflection data (Westbrook et al. 2008b; Plaza-Faverola et al. 2010).

The OBE CSEM data processing is described by Attias et al. (2016). We used a similar methodology to process the Vulcan CSEM data. In brief, we followed Myer et al.'s (2011) robust processing scheme. Several additional processing steps were implemented, designed to consider limitations specific to this survey (see Attias et al. (2016) for further details). The Vulcan CSEM data were Fourier transformed to the frequency domain and stacked over $60 \mathrm{~s}$ intervals $(\sim 46 \mathrm{~m}$ spacing between data points), yielding amplitude and phase data. The processed data were then merged with the navigational information from DASI and Vulcan. The navigational data indicate minimal geometric perturbations during deep-tow operations due to the regionally flat bathymetry, as shown in Fig. 2. 
Attias et al., (2018), manuscript for Geophys. J. Int.

\subsection{OBE-based Versus Vulcan-based CSEM System}

A CSEM system with increasing source-receiver offset (OBE-based CSEM) is commonly used in hydrocarbon exploration where reservoirs can be found several kilometres beneath the seafloor (e.g., Ellingsrud et al. 2002; Constable \& Srnka 2007; Constable 2010; MacGregor \& Tomlinson 2014). However, OBE-based CSEM has some limitations, such as high operational costs, large navigational errors relative to towed receivers, saturation of the electric field sensors at short source-receiver offsets, and gaps in data coverage between widely spaced OBEs (Myer et al. 2012; Constable et al. 2016). Alternatively, a fixed-offset Vulcan-based CSEM survey helps in mitigating some of these limitations and allows for continuous recording of usable data. However, due to operational considerations, the maximum source-receiver offset of a Vulcan-based CSEM system to date is $\leq 1200 \mathrm{~m}$, as demonstrated by Constable et al. (2016). Given the limited source-receiver offset combined with the towing altitude $(\sim 50 \mathrm{~m})$, the Vulcan-based CSEM system is most suitable for imaging shallow targets $(\sim$ several hundred metres below the seafloor), such as gas hydrates (Goswami et al. 2015, 2016; Constable et al. 2016) and seafloor massive sulphide deposits (Gehrmann et al. 2017). Hence, the OBE and Vulcan data are sensitive to different depth ranges, and thus, complement each other. In addition to the inline field data, the Vulcan vertical field data provide unique constraints on lateral structure (Constable et al. 2016).

\section{PHASE ERROR MITIGATION}

The phase data acquired in this survey were subject to drift, caused by non-linear timing errors from the transmitter crystal clock (Constable 2013). The DASI transmitter uses a free-running clock that is not locked to GPS timing, and thus, is prone to drift. To address this issue, we corrected for an $\sim 85$ ms/day drift of DASI's crystal clock, as documented by Attias et al. (2016). We utilised the nominal waveform (a $1 \mathrm{~Hz}$ square wave) for data processing due to the absence of information regarding the true waveform generated by the DASI transmitter during this survey. Using the transmitter nominal waveform instead of the true waveform is a major source of data uncertainty. Therefore, we assigned the inversions with a conservative error structure to adequately accommodate the overall uncertainty of the data (see section 5), consistent with the results of the perturbation analysis performed by Attias et al. (2016).

GPS time tags recorded pre and post survey to monitor the time drift of the Vulcan crystal clock were incorporated during processing. However, the recorded time tags do not fully encompass the magnitude of the phase drift seen in the Vulcan data since the source of this additional phase drift is DASI's nominal waveform, as described above. Hence, the Vulcan phase data present limitations that 
required mitigation. The following sections describe the Vulcan phase drift issue and the approach that we applied to mitigate it.

\subsection{Vulcan Phase Drift}

For the OBE data obtained in this study, 1-D forward models conducted by Attias et al. (2016) indicate that the amplitude and phase data in background sediment reasonably match a $1 \Omega \mathrm{m}$ forward model response, for both the fundamental frequency $(1 \mathrm{~Hz})$ and the following odd harmonics that were used $(3,5,7,9,11 \mathrm{~Hz})$. This conclusion is supported by 2-D forward models obtained from the OBE data (not shown). However, 2-D forward models performed on the Vulcan data suggest that for background sediment, although both the amplitude and phase data of the fundamental frequency approximately coincide with the $1 \Omega \mathrm{m}$ forward model response, the phase data of the following odd harmonics are significantly shifted from the $1 \Omega \mathrm{m}$ forward response (Fig. 3). Amplitude and phase inversions, performed with the original phase data of Vulcan, failed to converge to RMS misfit targets $<2$, presenting unrealistic resistivity models, poor model to data fits and high normalised residuals (further details in section 6.1.1). According to the regional geology (e.g., Senger et al. 2010) it is implausible that the background sediments will have a resistivity that is substantially lower than $1 \Omega \mathrm{m}$, as indicated from inversions using the original unshifted phase data (Figs $3 b, c$ and d). Therefore, we infer that the additional drift seen in the Vulcan phase data is due to a combined effect of non-linear DASI clock drift and differences between the true transmitter source waveform and the nominal waveform used for processing. Constable et al. (2016) demonstrated that limitations of the Vulcan crystal clock could be mitigated by sending GPS synchronised timing pulses from the EM transmitter to Vulcan. Although non-linear drift for the Vulcan clock is possible, it is unlikely that this is the source of the additional drift since the Vulcan clock drifted at a rate of less than $4 \mathrm{~ms} /$ day between the start and end of each tow line. The more probable source is the non-linear drift in DASI's clock, which at some fraction of $85 \mathrm{~ms} /$ day would be large enough to account for the residual drift evident in the data. Furthermore, the DASI clock drift itself was inferred from the Vulcan data and thus has some uncertainty.

\subsection{Vulcan Phase Correction}

We employ a pragmatic approach to resolve the drifts observed in the Vulcan phase data, based on OBE 1-D and 2-D forward model responses. These forward models suggest that the resistivity of the background sediment at CNE03 is about $1 \Omega \mathrm{m}$, consistent with a resistivity profile obtained from a nearby well-log (Senger et al. 2010). Thus, we are confident that the Vulcan phase data (in background sediment areas) should also roughly match the $1 \Omega \mathrm{m}$ 2-D forward model response for the four frequencies we used $(1,3,5,7 \mathrm{~Hz})$. 
Attias et al., (2018), manuscript for Geophys. J. Int.

In order to fit the phase data to the resistivity of the background sediment, we shifted the phase data of both the inline and vertical electric fields at each frequency to coincide with the $1 \Omega \mathrm{m}$ forward response. The phase shifts required for the inline and vertical electric fields were averaged to obtain a single time shift (for each towline) to be applied for all used frequencies, both for the inline and vertical electric field components. The applied time shifts are as follows: 5.5, 9.3, 5.5, 4.8, and $2.1 \mathrm{~ms}$ for survey line 1s, line 1n, line 2, line 3 and line 4, respectively.

We note that each survey line required a different time shift since the DASI transmitter was switched off at the end of each towline, and thus, each survey line was treated independently. Overall, our inversions converged to RMS misfit targets $<1.0$ while presenting adequate model to data fits with small normalised residuals, yielding resistivity models that are geologically plausible (further details in sections 6.1 and 6.2).

\section{INVERSION PARAMETERIZATION}

To invert the OBE and Vulcan data for electrical resistivity, we employed the open-source MARE2DEM software, a 2-D nonlinear regularized inversion method that utilises a parallel goal-oriented adaptive finite-element algorithm (Key 2016). MARE2DEM uses Occam's inversion, which searches for the smoothest model that fits the data to a predefined root-mean-square (RMS) target misfit (Constable et al. 1987; deGroot Hedlin \& Constable 1990). We inverted for phase and logarithmically scaled amplitude, which stabilises the inversion and reduces the time to convergence compared with linearly scaled amplitude inversion (Wheelock et al. 2015).

\subsection{Starting Model Parameters}

The starting model discretisation includes fixed parameters for a $10^{13} \Omega \mathrm{m}$ air layer, 12 laterally stratified seawater layers with resistivity values ranging between $0.26-0.33 \Omega \mathrm{m}$, and $1 \Omega \mathrm{m}$ half-space for the sub-seafloor region. The sub-seafloor mesh is discretized with quadrilateral elements (Key 2016), which reduces the number of free parameters to be solved by up to $\sim 50$ per cent and therefore shortens the inversion runtime in comparison to Delaunay triangulation mesh (Myer et al. 2015). The quadrilateral mesh is particularly advantageous when the seafloor receiver spacing is much wider than the depth of interest, whereby using wide and thin quadrilaterals provides fine depth scale while limiting the number of free parameters between adjacent receivers (Key 2016). To enhance the horizontal model smoothness (and hence minimise vertical structures), we increased the spatial horizontal to vertical roughness penalty weight from the default value of three up to six (see supporting information).

Anisotropic inversions of the OBE data from Attias et al. (2016) suggest that only a moderate 
electrical anisotropy exists beneath the CNE03 pockmark since the vertical resistivity is $\sim 1-1.2$ times greater than the horizontal resistivity. Thus, the CNE03 pipe-like resistivity structure can be sufficiently constrained by isotropic inversion. Therefore, all inversion models presented here are isotropic.

\subsection{Finite Dipole Inversion}

To enhance the accuracy of our models, we inverted the data using finite dipole lengths (rather than point dipole) for both the source and receivers. Although finite dipoles substantially increase the computational cost, they yield significantly more accurate forward model responses relative to a point dipole approximation in cases where the source-receiver offset is less than $\sim 4$ times the dipole length (Streich \& Becken 2011), as applied in this study (section 3). Our finite dipole inversions produced models that show a significantly higher sensitivity of the data to model parameters than other studies that applied point dipole inversions using MARE2DEM (further details in sections 5.5 and 6.3).

\subsection{Data Uncertainty}

The parameters of all inversion models presented here are described in Table 1. In summary, the OBE inversions include data from the inline electric field at six frequencies $(1,3,5,7,9,11 \mathrm{~Hz})$, whereas the Vulcan inversions use data from the inline and vertical electric fields at four frequencies $(1,3,5$, $7 \mathrm{~Hz}$ ), chosen in accordance with each instrument's noise floor. Uncertainty and perturbation analysis based on the survey geometry, DASI nominal waveform, and OBE dataset suggest an amplitude error of 4 per cent and phase error of $2.29^{\circ}$ (as derived from the amplitude-phase uncertainty relation: $\boldsymbol{\delta} \phi=\boldsymbol{\delta} r / \boldsymbol{r} * 180 / \pi$; where $\boldsymbol{\delta} \phi$ represents the phase uncertainty and $\boldsymbol{\delta} r$ the uncertainty in amplitude) for the OBE inline electric field (Attias et al. 2016).

Here, to calculate the uncertainty in Vulcan amplitude and phase data, we conducted an additional navigational perturbation error analysis, similar to the analysis demonstrated by Myer et al. (2015) and Constable et al. (2016). Our analysis was performed by calculating the 2-D forward model responses for perturbations applied to different navigational parameters. The DASI dip and azimuth, as well as the Vulcan roll and pitch parameters, were perturbed by $\pm 0.5^{\circ}$, whereas the altitude of DASI and Vulcan were perturbed by \pm 1 meter. Only a single navigational parameter was perturbed per forward model. The calculated forward response of each perturbation was then compared with the forward response obtained from the original unperturbed geometry. By summing the relative difference between all of the perturbed and unperturbed model responses, we obtained a frequency dependent error structure for each transmitter-receiver position along the profile of survey line $1 \mathrm{n}$. This perturbation analysis indicates that navigational errors introduce an averaged uncertainty of 3.8 per cent and 4.9 per cent for the amplitude, and $2.17^{\circ}$ and $2.80^{\circ}$ for the phase of the Vulcan inline (Ey) and vertical 
(Ez) electric field components, respectively. Therefore, we assigned an error structure of 4 per cent and 5 per cent in amplitude, and $2.29^{\circ}$ and $2.86^{\circ}$ in phase for the Vulcan Ey and Ez data, respectively (Table 1). We note that this error structure was assigned to all frequencies due to the following reasons: (i) this approach was previously used in Vulcan studies (Goswami et al. 2016; Constable et al. 2016), since the towed receiver system is highly resistant to inline source-receiver range errors (Constable et al. 2016), (ii) initial test inversions with different error per each frequency produced similar models, and (iii) maintain consistency with the error structure applied to the OBE data both here and in Attias et al. (2016). Preliminary inversions using a lower error floor of 3 and 4 per cent for the Vulcan Ey and Ez data produced excessively rough models that appear geologically implausible, likely due to the overfitting of data. This result concurs with the error estimates from our perturbation analysis and supports the validity of the applied error structure. A summary of the different sources of data errors and their relative importance to the results is given in the supporting information (Table 1).

\subsection{RMS Target Misfit}

To avoid overfitting the data, the RMS target misfit assigned to the inversion of each towline was either $0.95,0.9$ or 0.85 , depending on the data error structure and resulting inversion model roughness. In an ideal scenario, the RMS misfit should always be 1.0 if an accurate error structure is assigned. Nevertheless, Vulcan inversions that converged to RMS misfit targets of 1.0 with error floors of 3 and 4 per cent (as discussed above) yielded unsatisfactory models with excessive model roughness. Therefore, since data uncertainty and RMS misfit are inversely related, we increased the error structure from 3 and 4 per cent to 4 and 5 per cent, and then gradually lower the RMS target misfit below 1.0 until we produced consistent and geological plausible models for all towlines. We found that seeking for the ideal inversion model by subtly altering the RMS target misfit rather than changing the error structure gives a more finely tuned control over the inversion parameterization. Although conservative, this approach is time efficient and particularly useful when the uncertainties are not fully constrained, as demonstrated by previous studies (e.g., Key et al. 2014; Orange et al. 2014; Constable et al. 2015; Goswami et al. 2015).

\subsection{Model Sensitivity}

We performed a linearized sensitivity analysis to the MARE2DEM inversion models by evaluating the model Jacobian matrix J (e.g., Farquharson \& Oldenburg 1996; MacGregor et al. 2001; Key 2016). The Jacobian sensitivity matrix evaluates the data sensitivity to model parameters, where the rows of the uncertainty weighted Jacobian matrix are summed over all data and normalised by the area of each parameter cell (Farquharson \& Oldenburg 1996; Schwalenberg et al. 2002). 
The Jacobian sensitivity is plotted as percentile contours, where for example, a value $>=0.5$ indicates that these sensitivities are in the top half of the entire sensitivity range. Since percentile values are relative and the Jacobian sensitivity is mesh specific as well as dependent upon various model parameters, we only discuss model sensitivity in qualitative terms rather than quantitative. Goswami et al. (2016) applied the same approach to describe the Vulcan data sensitivity to the model parameters.

We co-rendered the inversion models with the $\mathbf{J}$ contours to demonstrate the high sensitivity range that exists across each model between the seafloor ( $725 \mathrm{~m}$ depth) and near the BGHSZ (860 m depth). For this purpose, we chose the following $\mathbf{J}$ contour values: 0.5, 0.7, 0.8, and 0.95, which best describe the relative distribution of the sensitivity. These $\mathbf{J}$ contour values were used for all models thus enabling us to assess how the model sensitivity of each towline varies when inverting the OBE and Vulcan datasets separately and collectively, as presented in sections 6.2 and 6.3. Since the model sensitivity decays rapidly below $860 \mathrm{~m}$ depth and the model resistivity decreases back to the starting model value of $1 \Omega \mathrm{m}$ (Fig. 2, supporting information), all the inversion models presented here are cut-off at $860 \mathrm{~m}$ depth.

\section{RESULTS}

We present results from a series of 2.5-D CSEM inversions performed on the Vulcan data alone as well as the combination of the OBE and Vulcan data. The feasibility of high-resolution CSEM is demonstrated by a comparison between unconstrained and seismically constrained inversions, which were applied to the OBE+Vulcan combined data. Additionally, a synthetic study was conducted to evaluate the variation in model sensitivity to shallow and deep features.

\subsection{Vulcan Resistivity Models}

Inversions using only Vulcan data for towlines 1-4 are shown in Fig. 4. These Vulcan inversions converged to the assigned RMS target misfits (Table 1) within a predefined tolerance of 1 per cent. The CNE03 gas hydrate pipe-like structure is well resolved at the intersection of towlines $1 \mathrm{n}$ and 2, consistent with the results of the OBE inversions (Attias et al. 2016). In total, we identified ten new shallow vertical resistors from the inverted Vulcan data, of which four are prominent features $(\geqslant 2 \Omega \mathrm{m}$ ). One of the resistive structures is located at the centre of line $1 \mathrm{~s}$, extending $\sim 100 \mathrm{~m}$ laterally and at least $\sim 90 \mathrm{~m}$ vertically (Fig. 4). Another resistor is located in the NNW part of line 2, exhibiting dimensions of $\sim 120 \mathrm{~m}$ and $\sim 30 \mathrm{~m}$ in the horizontal and vertical directions, respectively (Fig. 4). Two additional resistive structures are located on line 3 , showing a lateral extent of $\sim 80 \mathrm{~m}$ and vertical elongation of $\sim 70 \mathrm{~m}$ (Fig. 4). 
These newly discovered pipe-like resistive structures are most likely caused by the presence of gas hydrate/free gas in fluid flow conduits (Bünz et al. 2003; Westbrook et al. 2008a; Plaza-Faverola et al. 2010), with a minor contribution of methane-derived shallow authigenic carbonates, as documented at adjacent pockmarks in near-seafloor sediments (Hovland et al. 2005; Mazzini et al. 2006). None of the four primary resistive structures shows bathymetric expressions to suggest the existence of pockmarks at these locations (Fig. 1).

The upper layer of the Vulcan inversion models show slightly elevated lateral resistivity (Fig. 4), which is consistent with the OBE inversion models (Attias et al. 2016). This moderate resistivity most likely results from either small amounts of hydrates or shallow authigenic carbonates that are distributed laterally near the seafloor (Mazzini et al. 2006; Ivanov et al. 2010). Beneath this upper layer, most of the model shows $\sim 1 \Omega \mathrm{m}$ resistivity that is representative of the regional background sediment (Senger et al. 2010). A laterally extensive moderate increase in resistivity is observed in the deepest part (between $\sim 840-860 \mathrm{~m}$ ) of the Vulcan models (Fig. 4). We attribute this increase in resistivity to sediment compaction rather than the presence of hydrates (e.g., Cook \& Tost 2014), since the lateral existence of hydrates at this region, is not supported by coincident seismic reflection data (Westbrook et al. 2008b) or P-wave tomography (Plaza-Faverola et al. 2010).

\subsubsection{Inversions Residuals}

Fig. 5 shows a comparison between the model to data fit and normalised residuals of inversions applied to towline 2 data, with shifted and unshifted phase. In the shifted phase inversion (Figs $5 \mathrm{e}-\mathrm{h}$ ), both the Ey and Ez electric field phase components exhibit normalised residuals that are significantly lower than the residuals of the inversion performed with unshifted phase data (Figs 5a-d), whereas indistinguishable difference between the residuals of the amplitude data were observed (not shown). The CNE03 resistive anomaly moderately biases the normalised residuals of the Ey and Ez electric fields in a frequency dependent pattern (Fig. 5). This trend in residuals is observed for all the new resistive anomalies ( $\geqslant 2 \Omega \mathrm{m}$ ) detected along towlines 1-4 (Fig. 4). However, for the phase shifted inversion these subtle systematic residuals are small, well within the data errors (Figs 5e-h), and insignificant when the objective is to outline the spatial distribution of vertically distinctive structures. The observed positive/negative distribution of the normalised residuals in a frequency dependent pattern (Figs $5 \mathrm{f}$ and $\mathrm{h}$ ) concurs with the distribution of residuals presented by previous Vulcan studies (Constable et al. 2016; Goswami et al. 2016). Due to the low RMS misfit, we infer that the magnitude of the biased residuals is insignificant and therefore can be ignored since this most likely has little to no effect on the overall resistivity model. Furthermore, the Vulcan inversions are in good agreement with the OBE inversions for towlines 1n and 2 (Attias et al. 2016). We note that similar systemati- 
cally biased residuals were observed in the inversion of Vulcan data acquired from a methane hydrate province in the San Diego Trough (Constable et al. 2016).

\subsection{Real and Synthetic Model Comparison}

Synthetic studies are frequently used to characterise the sensitivity and resolution to be expected from a real data inversion, as well as to constrain any biases and ambiguities introduced by the survey layout (e.g., Myer et al. 2015; Naif et al. 2016). Thus, to confirm the authenticity of the newly detected resistive structures in the vicinity of the CNE03 pockmark, we conducted a synthetic study aiming to reproduce the resistivity model that resulted from inverting the Vulcan data of towline 3. To calculate the synthetic forward response, we used the frequency coverage and geometric configuration (e.g., DASI and Vulcan positions and geometry, data coverage) that were obtained in the survey for towline 3. The forward calculation was contaminated with Gaussian noise (4 per cent and 5 per cent to Ey and Ez amplitude data, $2.29^{\circ}$ and $2.86^{\circ}$ to Ey and Ez phase data, respectively), and then a synthetic inversion was run. We note that the added Gaussian noise has an identical magnitude as applied to the uncertainties of the real data inversion. Goswami et al. (2016) and Constable et al. (2016) applied a similar procedure to conduct synthetic studies to characterise the sensitivity of the Vulcan receiver to various resistivity structures.

Fig. 6 shows a comparison between line 3 real and synthetic data inversion models. Overall, this 2-D synthetic study successfully resolved the two vertical anomalous structures (Figs $6 \mathrm{~b}$ and c), comparable to the resistive vertical structures detected by the real data inversion (Fig. 6a). We acknowledge the probable limitations of a 2-D analysis to describe pipe-like structures that are most likely 3-D features; however, a 3-D analysis is beyond the scope of this paper. Nonetheless, our 2-D synthetic inversion exhibits sensitivity to the entire model space, as inferred from the adequate recovery of the background resistivity structure assigned to both flanks of the model (Figs $6 \mathrm{~b}$ and c). In the shallow part of the inversion model, the resistivities of the two vertical anomalies were recovered satisfactorily, whereas in the deepest part the resistivity is underestimated by $\sim 0.7 \Omega \mathrm{m}$.

Here, the Jacobian sensitivity provides a relative measure on how variations in model parameters affect the overall sensitivity to the data of this particular model. The deterioration of resolution and sensitivity with depth is consistent with the overall trend seen in the sensitivity contours, where both the real and synthetic inversion models exhibit peak sensitivity near the seafloor that drops off with depth (Figs 6a and c). Although the synthetic model suggests that the data are not sensitive enough to resolve the resistive layer in the deepest part of the model, the sensitivity of that layer in the real data inversion is relatively higher than in the synthetic inversion, where both inversions were performed using a similar error structure (Table 1). Nevertheless, in such analysis, it is essential to consider that 
sensitivity is highly model dependent, such that small modifications to the synthetic forward model may yield large changes in $\mathbf{J}$.

For the real data inversion of towline 3, Vulcan Ey data are more sensitive to the centre of the vertical resistive anomalies (presumably hydrate related) observed in both flanks of the model, whereas the Ez data are most sensitive to the edges of these pipe-like anomalous structures (Fig. 7). We note that the normalised residuals of the Ey amplitude data are biased in one direction (Fig. 7b). Some of this bias is associated with the regularization in the smooth inversion, but since the bias is well within the error bars, it is not considered a problem (Constable et al. 2016).

\subsection{OBE and Vulcan Combined Resistivity Models}

We performed a combined inversion of the data acquired by the OBE and Vulcan CSEM receivers, aiming to resolve the $\mathrm{CNE} 03$ pipe-like resistivity structure with the highest resolution possible. We inverted the OBE and Vulcan data separately and then simultaneously using both amplitude and phase information. Given the differences in transmitter-receiver offset, we expect the Vulcan data to constrain the shallow structure, whereas the OBE data will resolve the resistivity at the intermediate to deep parts of the model. Hence, some discrepancy is observed between the resistivity of the background sediment detected by the OBE inversions and the one resolved by the Vulcan inversions.

The OBE inversions exhibit substantial spatial variation in resistivity, where the sensitivity is highest at the model centre, coincident with the CNE03 pipe-like structure (Figs 8a and b). However, the background resistivity and the side boundaries of the vertical resistor beneath CNE03 in the OBE inversions are not well constrained due to unavoidable gaps in data coverage between the OBE receivers (Constable et al. 2016). The discrepancy observed in the CNE03 pipe-like structure between line 1n and line 2 OBE inversion models partially results from the presence of conductive anomalies positioned beneath each OBE, which are artefacts caused by minor navigational inaccuracies, as discussed in Attias et al. (2016).

Due to the continuous data coverage, the Vulcan inversions for line 1n and line 2 (Figs $8 \mathrm{c}$ and d) better constrain the regional background resistivity and both exhibit a distinctive resistivity structure beneath the CNE03 pockmark. The Vulcan (Figs 8c and d), unconstrained OBE+Vulcan (Figs 8e and f), and seismically constrained OBE+Vulcan (Figs $8 \mathrm{~g}$ and $\mathrm{h}$ ) inversion models all show subtle lateral variations in resistivity (striped pattern), which are likely to be inversion artefacts caused by uncertainties in Vulcan navigation; as inferred from (a) synthetic modelling (Fig. 1, supporting information), (b) the absence of such a pattern in the OBE models (Attias et al. 2016), and (c) corresponding seismic reflection data that lacks columnar blanking zones (indicative to the presence of hydrates) in the locations that the striped patterns appear (Plaza-Faverola et al. 2010; Attias et al. 2016). This resistive 
pattern is visually prominent due to the high vertical exaggeration $(\approx 40)$ and the smooth inversion colour scheme (Fig. 2, supporting information). We note that the striped pattern is a second order feature and has little to no effect on our main conclusions. Nevertheless, we conducted a series of test models using successively increasing spatial horizontal to vertical $(\mathrm{H}: \mathrm{V})$ roughness penalty weights $(>6)$, that smoothed the resistive striped pattern significantly (Fig. 3, supporting information). However, higher $\mathrm{H}: \mathrm{V}$ ratios also reduced the magnitude of the main vertical anomaly beneath $\mathrm{CNE} 03$ substantially and increased the lateral resistivity in the deep part of the model (Fig. 3, supporting information), which is inconsistent with seismically constrained OBE inversions (Attias et al. 2016). Therefore, all the models presented here were performed using a moderate $\mathrm{H}: \mathrm{V}$ ratio of six.

High $\mathbf{J}$ sensitivities are observed at the shallowest and deeper parts of the Vulcan models (Figs 8c and d). The Jacobian sensitivity contours are highly responsive to fluctuations in resistivity across the model space, with high resistivity regions associated with higher $\mathbf{J}$ sensitivities. A comparison between the OBE and Vulcan inversions shows that the sensitivity of the OBE inversions decreases rapidly both vertically and laterally with increasing distance from the receivers, whereas the sensitivity of the Vulcan inversions decreases vertically but laterally remains relatively constant (Figs 8a-d). Hence, the Vulcan data significantly improve the lateral resolution of the model, particularly in the shallow structure.

To utilise both the Vulcan and OBE datasets efficiently for improved imaging in simultaneous inversion, MARE2DEM employs a misfit weighting scheme that balances the contribution of each data subset to the overall misfit by normalising against the number of data points (Key 2016). Nonetheless, our combined inversions are predominantly constrained by the Vulcan data due to the greater data density and the addition of vertical electric field measurements.

In the line 1n Vulcan inversion, the CNE03 vertical resistor is relatively narrow at the seafloor and gradually widens and tilts with depth. In comparison with the Vulcan inversion, the OBE+Vulcan combined inversion improves the model resolution, as the resistor is narrower, sharper, and vertically aligned at depth (Figs 8c and e), which ideally coincides with the localized seismic blanking zone (Westbrook et al. 2008b; Plaza-Faverola et al. 2010); whereas in the Vulcan inversion the CNE03 resistor extends beyond the lateral boundaries of the blanking zone. This observation is supported by reduced variations in lateral resistivity and improved sensitivity in the combined inversions for both line $1 \mathrm{n}$ and line 2, compared with the OBE or Vulcan individual inversions. Thus, simultaneously inverting the OBE and Vulcan data improved the lateral sensitivity provided by the Vulcan data considerably (Figs 8c-f).

Next, to rigorously evaluate the degree of improvement in model resolution achieved by the combined inversion, we implemented model constraints from coincident seismic information on the 
CNE03 pipe-like structure. The CNE03 pipe-like structure was constrained using seismic reflection data (Westbrook et al. 2008b; Attias et al. 2016), by tracing the flanks of the columnar seismic blanking zone, whereas the deeper part of the pipe structure was also constrained by a P-wave velocity anomaly (Plaza-Faverola et al. 2010; Attias et al. 2016).

The seismically constrained line $1 \mathrm{n}$ and line 2 combined inversion models differ moderately from the unconstrained combined inversion models (Figs $8 \mathrm{~g}$ and $\mathrm{h}$ ). However, both sets of inversions imaged the CNE03 hydrate pipe-like structure in high resolution, yielding comparable final models (Figs 8eh). All of the line 2 inversions present an additional shallow and narrow vertical resistor within the gas hydrate stability zone, at a distance of $\sim 1.3 \mathrm{~km}$ along the model (Figs $8 \mathrm{~b}$,d,f and h). This resistor is most pronounced in the seismically constrained combined inversion model (Fig. 8h), collocated with a seismic diffraction (Plaza-Faverola et al. 2010). Thus, we postulate that this anomalous structure is primarily an additional accumulation of gas hydrate, possibly with a minor contribution of free gas (e.g., Bünz et al. 2003) and shallow authigenic carbonates (e.g., Mazzini et al. 2006).

A comparison of the normalised residuals from the unconstrained and constrained combined inversions of line $1 \mathrm{n}$ and line 2 indicate that the addition of the seismic constraints decreased the OBE and Vulcan amplitude data misfit by 10-15 per cent and increased the phase data misfit by 11-17 per cent. However, the residual distribution became more random for both the amplitude and phase data. Our amplitude only and phase only inversions (not shown) indicate that the phase data is more sensitive to the deep part $(>830 \mathrm{~m})$ rather than the shallow part $(<750 \mathrm{~m})$ of the model, whereas the amplitude data inversions detected both deep and shallow resistive features equally well. This opposite trend observed between the amplitude and phase misfits might be explained by either (a) the phase shift that was applied to the phase data initially, (b) the decrease in sensitivity in the deep region of the model (consequently to the addition of seismic constraints), or possibly the combination of both.

The Vulcan only inversions exhibit higher sensitivity to lateral changes in resistivity though poorer resolution of the vertical anomaly beneath the CNE03 pockmark, in comparison to the unconstrained and seismically constrained combined inversions (Figs $8 \mathrm{c}-\mathrm{h}$ ). Both the unconstrained and seismically constrained combined inversions resolved the anomalous structure beneath CNE03 with high resolution, where the unconstrained inversions show higher sensitivity to the models' deepest parts, as demonstrated by the $\mathbf{J}$ contours (Figs 8e-h). Our comparison between the OBE/Vulcan individual inversions and the unconstrained/constrained combined inversions illustrates the capability of the combined inversion to yield accurate high-resolution resistivity models of the subsurface independent of seismic constraints. 


\section{CONCLUSIONS}

We report the discovery of four new pipe-like resistive structures in the vicinity of the CNE03 pockmark, as derived from the CSEM towed receiver data. This discovery supports the abundance and density of gas hydrate accumulations previously inferred in the Nyegga region. Additionally, 2.5-D CSEM combined inversions of towed and ocean-bottom electric field receiver data resolved the gas hydrate resistivity structure beneath CNE03 better than inversions of either dataset alone, as deduced from comparison with seismically constrained inversions. Our results demonstrate the capability of the marine CSEM technique to detect and constrain gas hydrate deposits in high resolution, particularly when hydrate accumulates in vertical to sub-vertical elongated structures. Hence, such combined inversion of CSEM datasets can effectively image and delineate various sub-seafloor shallow structures. The approach applied in this research may be useful in the study of oceanic seafloor massive sulphide deposits, groundwater reservoirs, and sub-sea permafrost, as well as in the monitoring of shallow $\mathrm{CO}_{2}$ geosequestration sites and geothermal systems.

\section{ACKNOWLEDGMENTS}

This paper forms part of the $\mathrm{PhD}$ studies of Eric Attias, funded by Rock Solid Images Ltd, the University of Southampton, and the National Oceanography Centre. The German Research Council funded the research cruise. OBE receivers were operated by the UK Ocean Bottom Instrumentation Consortium. TAM was supported by a Wolfson Research Merit Award. We thank Kerry Key for use of his MARE2DEM inversion algorithm, and Kim Senger, Peter K Kannberg, Chris Armerding, Jacob Perez and Matthew R Agius for productive discussions. Additionally, we thank Martin Sinha, Laurence North, Héctor Marín-Moreno and Yee Yuan Tan for operating the University of Southampton CSEM system, as well as the captain, crew and scientific party of Meteor Cruise M87/2, project COSY. Finally, we thank G. Michael Hoversten and two other anonymous reviewers for their insightful comments that helped to improve this paper. The data used in this paper are available via https://doi.pangaea.de/10.1594/PANGAEA.875644.

\section{REFERENCES}

Archer, D., 2007. Methane hydrate stability and anthropogenic climate change, Biogeosciences Discussions, 4(2), 993-1057.

Archer, D., Buffett, B., \& Brovkin, V., 2009. Ocean methane hydrates as a slow tipping point in the global carbon cycle, Proceedings of the National Academy of Sciences, 106(49), 20596-20601.

Attias, E., Weitemeyer, K., Minshull, T. A., Best, A. I., Sinha, M., Jegen-Kulcsar, M., Hölz, S., \& Berndt, C., 
2016. Controlled-source electromagnetic and seismic delineation of subseafloor fluid flow structures in a gas hydrate province, offshore Norway, Geophys. J. Int., 206(2), 1093-1110.

Boswell, R. \& Collett, T. S., 2011. Current perspectives on gas hydrate resources, Energy and environmental science, 4(4), 1206-1215.

Boswell, R., Yamamoto, K., Lee, S.-R., Collett, T., Kumar, P., \& Dallimore, S., 2014. Chapter 8 - Methane Hydrates, Elsevier.

Boswell, R., Shipp, C., Reichel, T., Shelander, D., Saeki, T., Frye, M., Shedd, W., Collett, T. S., \& McConnell, D. R., 2015. Prospecting for marine gas hydrate resources, Interpretation, 4(1), SA13-SA24.

Bünz, S., Mienert, J., \& Berndt, C., 2003. Geological controls on the Storegga gas-hydrate system of the mid-Norwegian continental margin, Earth Planet. Sci. Lett., 209(3-4), 291-307.

Chen, Y., Bian, Y., Haflidason, H., \& Matsumoto, R., 2011. Present and past methane seepage in pockmark CN03, Nyegga, offshore mid-Norway, in Proceedings of the 7th International Conference on Gas Hydrates (ICGH 2011), 17-21 July 2011, ICGH 2011, Edinburgh.

Collett, T. S. \& Boswell, R., 2012. Resource and hazard implications of gas hydrates in the northern gulf of mexico: Results of the 2009 joint industry project leg \{II\} drilling expedition, Mar. Petrol. Geol., 34(1), 1-3.

Collett, T. S., Johnson, A. H., Knapp, C. C., \& Boswell, R., 2009. Natural gas hydrates: a review, AAPG memoir, 89, 146-220.

Constable, S., 2010. Ten years of marine CSEM for hydrocarbon exploration, Geophysics, 75(5), 67-81.

Constable, S., 2013. Review paper: Instrumentation for marine magnetotelluric and controlled source electromagnetic sounding, Geophys. Prospect., 61(s1), 505-532.

Constable, S. \& Srnka, L. J., 2007. An introduction to marine controlled-source electromagnetic methods for hydrocarbon exploration, Geophysics, 72(2), WA3-WA12.

Constable, S., Orange, A., \& Key, K., 2015. And the geophysicist replied: "Which model do you want?", Geophysics, 80(3), E197-E212.

Constable, S., Kannberg, P. K., \& Weitemeyer, K., 2016. Vulcan: A deep-towed CSEM receiver, Geochem. Geophys. Geosyst., 17(3), 1042-1064.

Constable, S. C., Parker, R. L., \& Constable, C. G., 1987. Occam's inversion: A practical algorithm for generating smooth models from electromagnetic sounding data, Geophysics, 52(3), 289-300.

Cook, A. E. \& Tost, B. C., 2014. Geophysical signatures for low porosity can mimic natural gas hydrate: An example from Alaminos Canyon, Gulf of Mexico, J. Geophys. Res., 119(10), 7458-7472.

Cox, C. S., 1981. On the electrical conductivity of the oceanic lithosphere, Phys. Earth Planet. Inter., 25(3), 196-201.

Crutchley, G., Fraser, D., Pecher, I., Gorman, A., Maslen, G., \& Henrys, S., 2015. Gas migration into gas hydrate-bearing sediments on the southern Hikurangi margin of New Zealand, J. Geophys. Res., 120(2), 725-743.

deGroot Hedlin, C. \& Constable, S., 1990. Occam's inversion to generate smooth, two-dimensional models from magnetotelluric data, Geophysics, 55(12), 1613-1624. 
Dewangan, P. \& Ramprasad, T., 2007. Velocity and AVO analysis for the investigation of gas hydrate along a profile in the western continental margin of India, Mar. Geophys. Res., 28(3), 201-211.

Dickens, G. R., 2003. Rethinking the global carbon cycle with a large, dynamic and microbially mediated gas hydrate capacitor, Earth Planet. Sci. Lett., 213(3), 169-183.

Edwards, N., 2005. Marine controlled source electromagnetics: principles, methodologies, future commercial applications, Surv. Geophys., 26(6), 675-700.

Edwards, R. N., 1997. On the resource evaluation of marine gas hydrate deposits using sea-floor transient electric dipole-dipole methods, Geophysics, 62(1), 63-74.

Ellingsrud, S., Eidesmo, T., Johansen, S., Sinha, M., MacGregor, L., \& Constable, S., 2002. Remote sensing of hydrocarbon layers by seabed logging (SBL): Results from a cruise offshore Angola, The Leading Edge, 21(10), 972-982.

Engelmark, F., Mattsson, J., McKay, A., \& Du, Z., 2014. Towed streamer EM comes of age, First Break, 32(4).

Evans, R. \& Key, K., 2016. Mapping Offshore Freshwater Deposits Using Electromagnetic Methods, in Near Surface Geoscience 2016 - Second Applied Shallow Marine Geophysics Conference, pp. 10.3997/22144609.201602169.

Farquharson, C. \& Oldenburg, D., 1996. Approximate sensitivities for the electromagnetic inverse problem, Geophys. J. Int., 126(1), 235-252.

Galiana, S. \& Garcia, X., 2015. A Formulation for the 2.5-D CSEM Inverse Problem Using a PDE Constrained Optimization, in 77th EAGE Conference.

Gehrmann, R., Tan, I., Minshull, T., Ollington, B., Attias, E., North, L., Hölz, S., Sommer, M., Jegen, M., Szitkar, F., Graber, S., Petersen, S., Schröder, H., Bialas, J., Gill, A., Vardy, M., \& Murton, B., 2017. Massive sulphide exploration with controlled source electromagnetics at the Mid-Atlantic Ridge, in MARELEC 2017. Goswami, B. K., Weitemeyer, K. A., Minshull, T. A., Sinha, M. C., Westbrook, G. K., Chabert, A., Henstock, T. J., \& Ker, S., 2015. A joint electromagnetic and seismic study of an active pockmark within the hydrate stability field at the Vestnesa Ridge, West Svalbard margin, J. Geophys. Res., 120(10), 6797-6822.

Goswami, B. K., Weitemeyer, K. A., Minshull, T. A., Sinha, M. C., Westbrook, G. K., \& Marín-Moreno, H., 2016. Resistivity image beneath an area of active methane seeps in the west Svalbard continental slope, Geophys. J. Int., 207(2), 1286-1302.

Hansen, K., Panzner, M., Shantsev, D., \& Mittet, R., 2016. TTI inversion of marine CSEM data, in SEG Technical Program Expanded Abstracts 2016, pp. 1014-1018, Society of Exploration Geophysicists.

Harris, P. \& MacGregor, L., 2006. Determination of reservoir properties from the integration of CSEM and seismic data, First Break, 24, 15-21.

Harris, P., Du, Z., MacGregor, L., Olsen, W., Shu, R., \& Cooper, R., 2009. Joint interpretation of seismic and CSEM data using well log constraints: An example from the Luva Field, First Break, 27(5), 73-81.

Hölz, S. \& Jegen, M., 2016. How to Find Buried and Inactive Seafloor Massive Sulfides Using Transient Electromagnetics - A Case Study from the Palinuro Seamount, in EAGE/DGG Workshop on Deep Mineral 
Exploration.

Hovland, M., Gardner, J., \& Judd, A., 2002. The significance of pockmarks to understanding fluid flow processes and geohazards, Geofluids, 2(2), 127-136.

Hovland, M., Svensen, H., Forsberg, C. F., Johansen, H., Fichler, C., Fosså, J. H., et al., 2005. Complex pockmarks with carbonate-ridges off mid-Norway: products of sediment degassing, Mar. Geol., 218(1), 191206.

Hustoft, S., Bünz, S., \& Mienert, J., 2010. Three-dimensional seismic analysis of the morphology and spatial distribution of chimneys beneath the Nyegga pockmark field, offshore mid-Norway, Basin Res., 22(4), 465480.

Hyndman, R. \& Spence, G., 1992. A seismic study of methane hydrate marine bottom simulating reflectors, J. Geophys. Res., 97(B5), 6683-6698.

Ivanov, M., Mazzini, A., Blinova, V., Kozlova, E., Laberg, J.-S., Matveeva, T., Taviani, M., \& Kaskov, N., 2010. Seep mounds on the southern Vøring plateau (offshore norway), Mar. Petrol. Geol., 27(6), 1235-1261.

Jaysaval, P., Sen, M., Arnulf, A., \& Denel, B., 2017. Fast 2.5 D controlled-source electromagnetic inversion using a Schur complement based frequency-domain finite-difference modeling, in SEG Technical Program Expanded Abstracts 2017, pp. 1121-1125, Society of Exploration Geophysicists.

Jorgenson, M., Yoshikawa, K., Kanevskiy, M., Shur, Y., Romanovsky, V., Marchenko, S., Grosse, G., Brown, J., \& Jones, B., 2008. Permafrost characteristics of Alaska, in Proceedings of the Ninth International Conference on Permafrost, vol. 29, pp. 121-122, University of Alaska: Fairbanks.

Kai, C., Wenbo, W., Ming, D., Zhongliang, W., \& Gang, Y., 2015. A new marine controlled-source electromagnetic receiver with an acoustic telemetry modem and arm-folding mechanism, Geophys. Prospect., 63(6), $1420-1429$.

Key, K., 2016. MARE2DEM: a 2-D inversion code for controlled-source electromagnetic and magnetotelluric data, Geophys. J. Int., 207(1), 571-588.

Key, K., Du, Z., Mattsson, J., McKay, A., \& Midgley, J., 2014. Anisotropic 2.5D inversion of Towed Streamer EM data from three North Sea fields using parallel adaptive finite elements, in 76th EAGE Conference, vol. 10, pp. 2214-4609.

Korenaga, J., Holbrook, W., Singh, S., \& Minshull, T., 1997. Natural gas hydrates on the southeast US margin: Constraints from full waveform and travel time inversions of wide-angle seismic data, J. Geophys. Res., 102, 15-345.

Kvenvolden, K., Ginsburg, G., \& Soloviev, V., 1993. Worldwide distribution of subaquatic gas hydrates, Geo-Mar. Lett., 13(1), 32-40.

Lee, J. H., Baek, Y. S., Ryu, B. J., Riedel, M., \& Hyndman, R. D., 2005. A seismic survey to detect natural gas hydrate in the East Sea of Korea, Mar. Geophys. Res., 26(1), 51-59.

Li, A., Davies, R. J., \& Yang, J., 2016. Gas trapped below hydrate as a primer for submarine slope failures, Mar. Geol., 380, 264-271.

Lodolo, E., Camerlenghi, A., Madrussani, G., Tinivella, U., \& Rossi, G., 2002. Assessment of gas hydrate 
and free gas distribution on the South Shetland margin (Antarctica) based on multichannel seismic reflection data, Geophys. J. Int., 148(1), 103-119.

MacGregor, L. \& Tomlinson, J., 2014. Marine controlled-source electromagnetic methods in the hydrocarbon industry: A tutorial on method and practice, Interpretation, 2(3), SH13-SH32.

MacGregor, L., Sinha, M., \& Constable, S., 2001. Electrical resistivity structure of the Valu Fa Ridge, Lau Basin, from marine controlled-source electromagnetic sounding, Geophys. J. Int., 146(1), 217-236.

MacGregor, L., Bouchrara, S., Tomlinson, J., Strecker, U., Fan, J., Ran, X., \& Yu, G., 2012. Integrated analysis of CSEM, seismic and well log data for prospect appraisal: a case study from West Africa, First Break, 30(4), $77-82$.

MacKay, M. E., Jarrard, R. D., Westbrook, G. K., \& Hyndman, R. D., 1994. Origin of bottom-simulating reflectors: geophysical evidence from the Cascadia accretionary prism, Geology, 22(5), 459-462.

Marín-Moreno, H., Minshull, T. A., Westbrook, G. K., \& Sinha, B., 2015. Estimates of future warminginduced methane emissions from hydrate offshore west Svalbard for a range of climate models, Geochem. Geophys. Geosyst., 16(5), 1307-1323.

Mazzini, A., Svensen, H., Hovland, M., \& Planke, S., 2006. Comparison and implications from strikingly different authigenic carbonates in a Nyegga complex pockmark, G11, Norwegian Sea, Mar. Geol., 231(1), $89-102$.

McConnell, D. R., Zhang, Z., \& Boswell, R., 2012. Review of progress in evaluating gas hydrate drilling hazards, Mar. Petrol. Geol., 34(1), 209-223.

McKay, A., Mattson, J., \& Du, Z., 2015. Towed Streamer EM-reliable recovery of sub-surface resistivity, First Break, 33(4), 75-85.

Milkov, A. V. \& Sassen, R., 2002. Economic geology of offshore gas hydrate accumulations and provinces, Mar. Petrol. Geol., 19(1), 1-11.

Minshull, T. A., Sinha, M. C., \& Peirce, C., 2005. Multi-disciplinary, sub-seabed geophysical imaging, Sea Technology, 46(10), 27-31.

Morten, J. P., Roth, F., Karlsen, S. A., Timko, D., Pacurar, C., Olsen, P. A., Nguyen, A. K., \& Gjengedal, J., 2012. Field appraisal and accurate resource estimation from $3 \mathrm{~d}$ quantitative interpretation of seismic and csem data, The Leading Edge, 31(4), 447-456.

Mueller, H., Schwalenberg, K., Hilgenfeldt, C., \& von Dobeneck, T., 2016. Mapping Seafloor Massive Sulfides at the Central Indian Ridge with a Novel Central Loop Electromagnetic Profiler, in Near Surface Geoscience 2016 - First Conference on Geophysics for Mineral Exploration and Mining.

Myer, D., Constable, S., \& Key, K., 2011. Broad-band waveforms and robust processing for marine CSEM surveys, Geophys. J. Int., 184(2), 689-698.

Myer, D., Constable, S., Key, K., Glinsky, M. E., \& Liu, G., 2012. Marine CSEM of the Scarborough gas field, Part 1: Experimental design and data uncertainty, Geophysics, 77(4), E281-E299.

Myer, D., Key, K., \& Constable, S., 2015. Marine CSEM of the Scarborough gas field, Part 2: 2D inversion, Geophysics, 80(3), E187-E196. 
Naif, S., Key, K., Constable, S., \& Evans, R. L., 2016. Porosity and fluid budget of a water-rich megathrust revealed with electromagnetic data at the Middle America Trench, Geochem. Geophys. Geosyst., 17, 44954516.

Ojha, M., Sain, K., \& Minshull, T. A., 2010. Assessment of gas-hydrate saturations in the Makran accretionary prism using the offset dependence of seismic amplitudes, Geophysics, 75(2), C1-C6.

Orange, A., Constable, S., \& Key, K., 2014. 2D inversion of marine EM data-Validity and variation, in SEG Technical Program Expanded Abstracts 2014, pp. 711-715, Society of Exploration Geophysicists.

Park, J., Sauvin, G., Vöge, M., \& Vanneste, M., 2017. 2.5D Inversion and Joint Interpretation of Marine EM Data at Sleipner CO2 Storage, Energy Procedia, 114, 3989 - 3996.

Pinero, E., Marquardt, M., Hensen, C., Haeckel, M., \& Wallmann, K., 2013. Estimation of the global inventory of methane hydrates in marine sediments using transfer functions, Biogeosciences, 10(2), 959-975.

Plaza-Faverola, A., Westbrook, G. K., Ker, S., Exley, R. J., Gailler, A., Minshull, T. A., \& Broto, K., 2010. Evidence from three-dimensional seismic tomography for a substantial accumulation of gas hydrate in a fluid-escape chimney in the Nyegga pockmark field, offshore Norway, J. Geophys. Res., 115(B8).

Plaza-Faverola, A., Bünz, S., \& Mienert, J., 2011. Repeated fluid expulsion through sub-seabed chimneys offshore Norway in response to glacial cycles, Earth Planet. Sci. Lett., 305(3-4), 297-308.

Plaza-Faverola, A., Bünz, S., \& Mienert, J., 2012. The free gas zone beneath gas hydrate bearing sediments and its link to fluid flow: 3-D seismic imaging offshore mid-Norway, Mar. Geol., 291-294, 211-226.

Riboulot, V., Cattaneo, A., Lanfumey, V., Voisset, M., Cauquil, E., et al., 2011. Morphological signature of fluid flow seepage in the Eastern Niger Submarine Delta (ENSD), in Offshore Technology Conference, Houston, TX, USA. OTC 21744.

Riboulot, V., Sultan, N., Imbert, P., \& Ker, S., 2016. Initiation of gas-hydrate pockmark in deep-water Nigeria: Geo-mechanical analysis and modelling, Earth Planet. Sci. Lett., 434, 252-263.

Ruppel, C., 2011. Methane hydrates and contemporary climate change, Nature Education Knowledge, 3(10), 29.

Ruppel, C. D. \& Kessler, J. D., 2016. The Interaction of Climate Change and Methane Hydrates, Rev. Geophys.. Schwalenberg, K., Rath, V., \& Haak, V., 2002. Sensitivity studies applied to a two-dimensional resistivity model from the central andes, Geophys. J. Int., 150(3), 673-686.

Schwalenberg, K., Willoughby, E., Mir, R., \& Edwards, R., 2005. Marine gas hydrate electromagnetic signatures in Cascadia and their correlation with seismic blank zones, First Break, 23(4), 57-63.

Senger, K., Bünz, S., \& Mienert, J., 2010. First-Order Estimation of in-Place Gas Resources at the Nyegga Gas Hydrate Prospect, Norwegian Sea, Energies, 3(12), 2001-2026.

Sherman, D., Kannberg, P., \& Constable, S., 2017. Surface towed electromagnetic system for mapping of subsea Arctic permafrost, Earth Planet. Sci. Lett., 460, 97-104.

Shipley, T. H., Houston, M. H., Buffler, R. T., Shaub, F. J., McMillen, K. J., Ladd, J. W., \& Worzel, J. L., 1979. Seismic evidence for widespread possible gas hydrate horizons on continental slopes and rises, $A A P G$ bulletin, 63(12), 2204-2213. 
Singh, S. C., Minshull, T. A., \& Spence, G. D., 1993. Velocity structure of a gas hydrate reflector, Science, 260(5105), 204-207.

Sinha, M., Patel, P., Unsworth, M., Owen, T., \& MacCormack, M., 1990. An active source electromagnetic sounding system for marine use, Mar. Geophys. Res., 12(1-2), 59-68.

Sloan, E. D., 2003. Fundamental principles and applications of natural gas hydrates, Nature, 426(6964), 353363.

Streich, R. \& Becken, M., 2011. Electromagnetic fields generated by finite-length wire sources: comparison with point dipole solutions, Geophys. Prospect., 59(2), 361-374.

Sultan, N., Marsset, B., Ker, S., Marsset, T., Voisset, M., Vernant, A.-M., Bayon, G., Cauquil, E., Adamy, J., Colliat, J., et al., 2010. Hydrate dissolution as a potential mechanism for pockmark formation in the Niger delta, J. Geophys. Res., 115(B8).

Weitemeyer, K., Constable, S., Key, K., \& Behrens, J., 2006. First results from a marine controlled-source electromagnetic survey to detect gas hydrates offshore Oregon, Geophys. Res. Lett., 33(3).

Weitemeyer, K., Constable, S., \& Tréhu, A., 2011. A marine electromagnetic survey to detect gas hydrate at Hydrate Ridge, Oregon, Geophys. J. Int., 187(1), 45-62.

Westbrook, G., Chand, S., Rossi, G., Long, C., Bünz, S., Camerlenghi, A., Carcione, J., Dean, S., Foucher, J.-P., Flueh, E., et al., 2008a. Estimation of gas hydrate concentration from multi-component seismic data at sites on the continental margins of NW Svalbard and the Storegga region of Norway, Mar. Petrol. Geol., 25(8), 744-758.

Westbrook, G. K., Exley, R., Minshull, T., Nouzé, H., Gailler, A., et al., 2008b. High-resolution 3D seismic investigations of hydrate-bearing fluid-escape chimneys in the Nyegga region of the Vøring plateau, Norway, in Proceedings of the 6th International Conference on Gas Hydrates (ICGH 2008), Vancouver, BC, Canada, July 6-10, 2008.

Wheelock, B., Constable, S., \& Key, K., 2015. The advantages of logarithmically scaled data for electromagnetic inversion, Geophys. J. Int., 201(3), 1765-1780.

Wood, W., Lindwall, D., Gettrust, J., Sekharan, K., \& Golden, B., 2000. Constraints on gas or gas hydrate related wipeouts in seismic data through the use of physical models, Eos (Transactions, American Geophysical Union), 81(48), F639.

Xu, W. \& Ruppel, C., 1999. Predicting the occurrence, distribution, and evolution of methane gas hydrate in porous marine sediments, J. Geophys. Res., 104(B3), 5081-5095.

Yamamoto, K., Terao, Y., Fujii, T., Ikawa, T., Seki, M., Matsuzawa, M., \& Kanno, T., 2014. Operational overview of the first offshore production test of methane hydrates in the Eastern Nankai Trough, in Offshore Technology Conference, OTC-25243-MS, Houston, Tex, Offshore Technology Conference.

Zhang, Y. \& Key, K., 2016. MARE3DEM: A three-dimensional CSEM inversion based on a parallel adaptive finite element method using unstructured meshes, in SEG Technical Program Expanded Abstracts 2016, pp. 1009-1013, Society of Exploration Geophysicists. 
24 Attias et al., (2018), manuscript for Geophys. J. Int.

\section{${ }_{738}$ SUPPORTING INFORMATION}

${ }_{739}$ Additional Supporting Information can be found in the online version of this paper:

Table 1: A summary of the different sources of data errors and their relative importance to the results.

741 Fig. 1: Synthetic forward, and inversion models of Vulcan towed receiver.

Fig. 2: Vulcan inversion with a vertical exaggeration of $\approx 20$.

Fig. 3: Vulcan inversions with increasing spatial horizontal to vertical roughness regularization. 


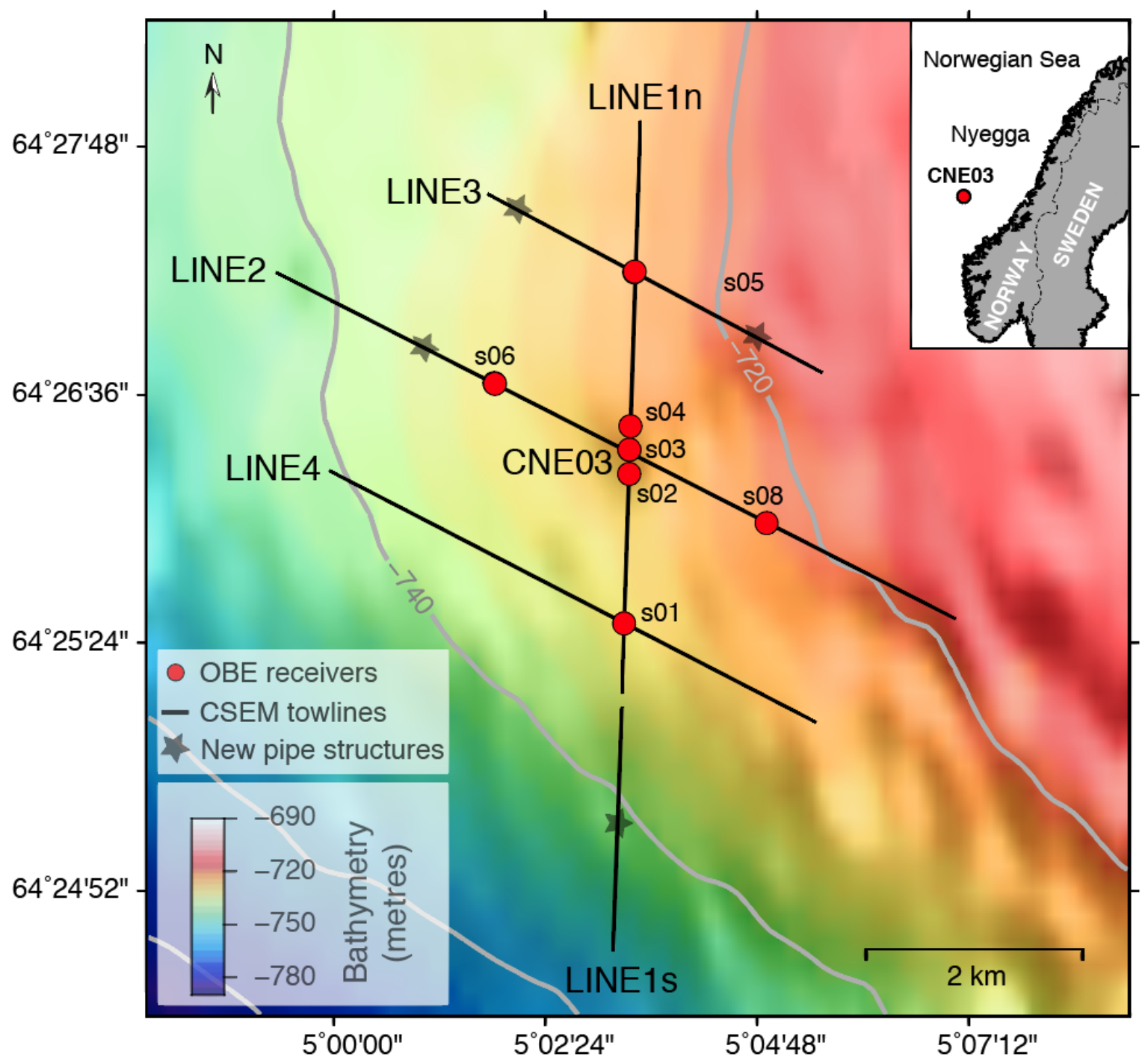

Figure 1. A map illustrating the CSEM survey layout at the CNE03 pockmark area. The data were recorded by seven OBEs surrounding the CNE03 pockmark. Survey lines 1s (south), 1n (north), 2, 3, and 4 were collected using seven OBEs, the DASI transmitter and a towed receiver (Vulcan). Line 1 was divided into two separate towlines because the transmitter was switched off and on, as done between each towline. Towlines $1 \mathrm{n}$ and 2 are coincident with seismic reflection data (Westbrook et al. 2008b). The stars denote the locations of newly discovered resistive pipe-like structures (further details in section 6.1). Inset map: the location of the CNE03 pockmark, at Nyegga region, offshore Norway. 
(a)

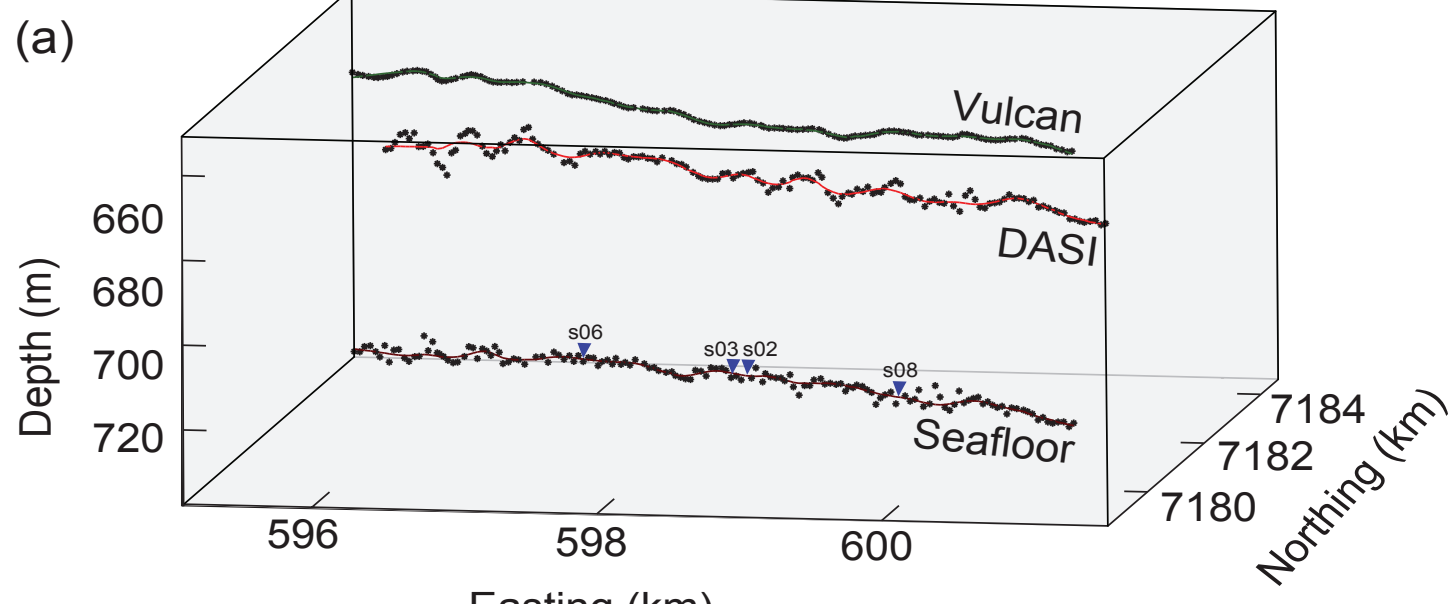

(b)

\section{Easting $(\mathrm{km})$}

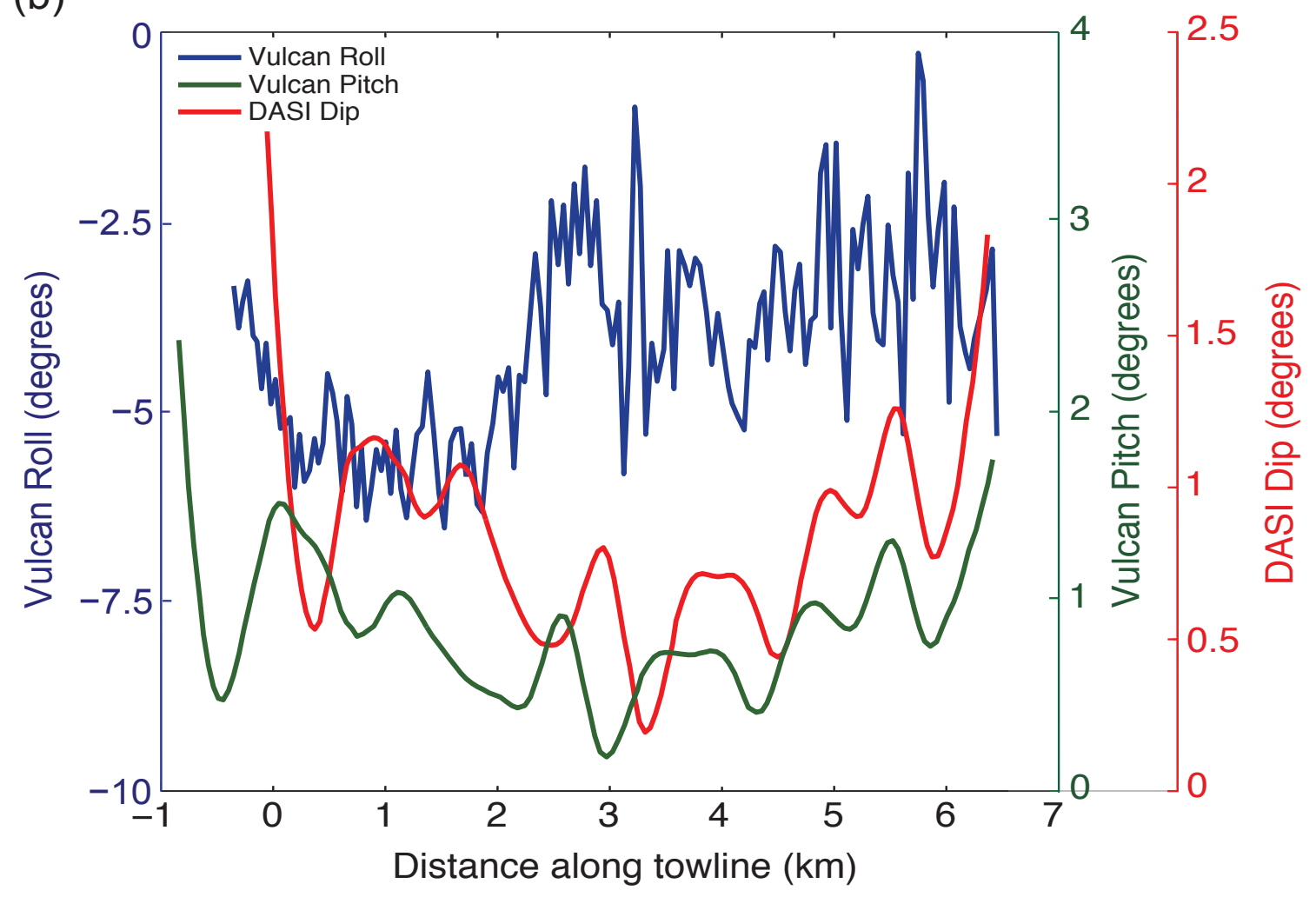

Figure 2. CSEM system navigation along towline 2. (a) Position and depth of the seafloor, OBE, DASI, and Vulcan. Blue inverted triangles represent the OBE, black dots the raw data and lines the smoothed data that were used for the inversion. (b) Plot showing DASI dip, Vulcan pitch, and roll information employed by the inversion. The DASI dip is assumed, derived from the Vulcan pitch data. Vulcan pitch and DASI dip data are smoothed. We note that for all survey lines, the difference between Vulcan and DASI heading is $\leq 4^{\circ}$. 

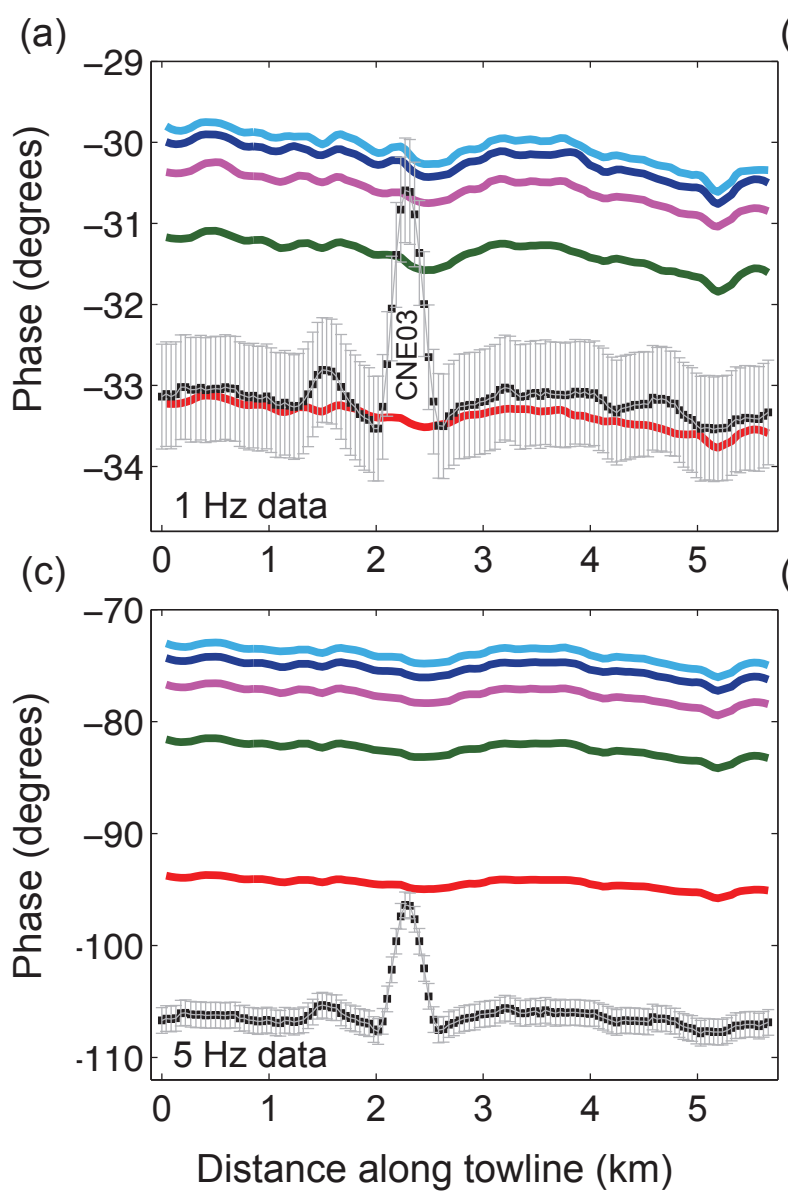

(b)

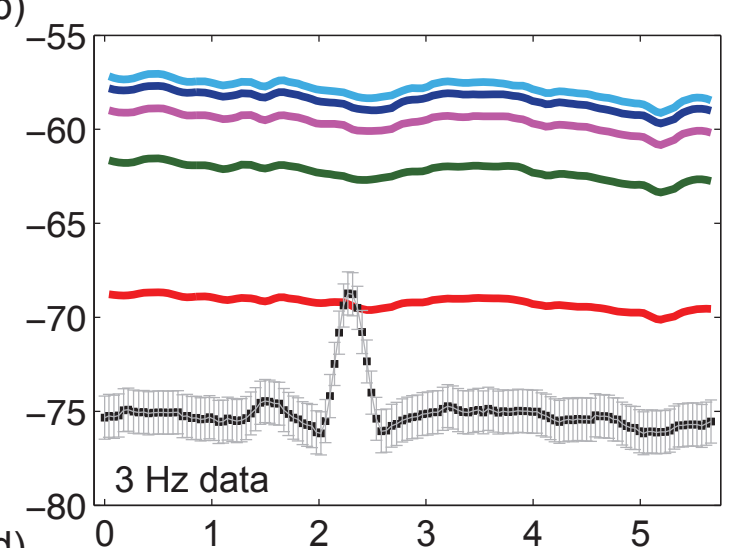

(d)

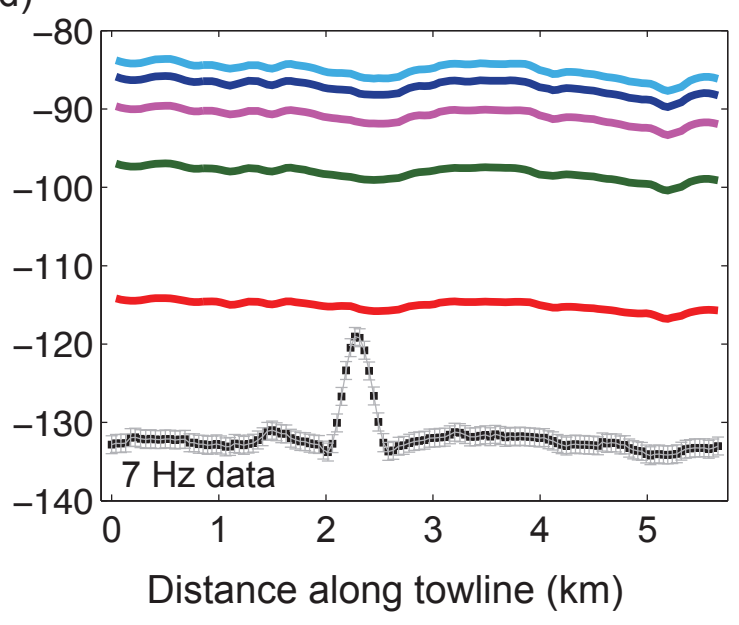

- Inline phase data

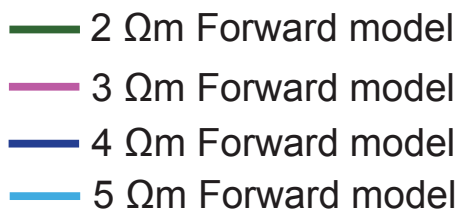

Figure 3. Line 1n: Vulcan inline electric field unshifted phase data versus 2-D forward models. (a) The $1 \mathrm{~Hz}$ phase data are in proximity to the $1 \Omega \mathrm{m}$ forward model at background sediment areas. The phase data at the peak of the CNE03 anomaly corresponds to the $3 \Omega \mathrm{m}$ forward model. (b) $3 \mathrm{~Hz}$ phase data. (b) $5 \mathrm{~Hz}$ phase data. (b) $7 \mathrm{~Hz}$ phase data. Note that the 3,5, and $7 \mathrm{~Hz}$ harmonics successively drift further away from the $1 \Omega \mathrm{m}$ forward model response. 
28 Attias et al., (2018), manuscript for Geophys. J. Int.

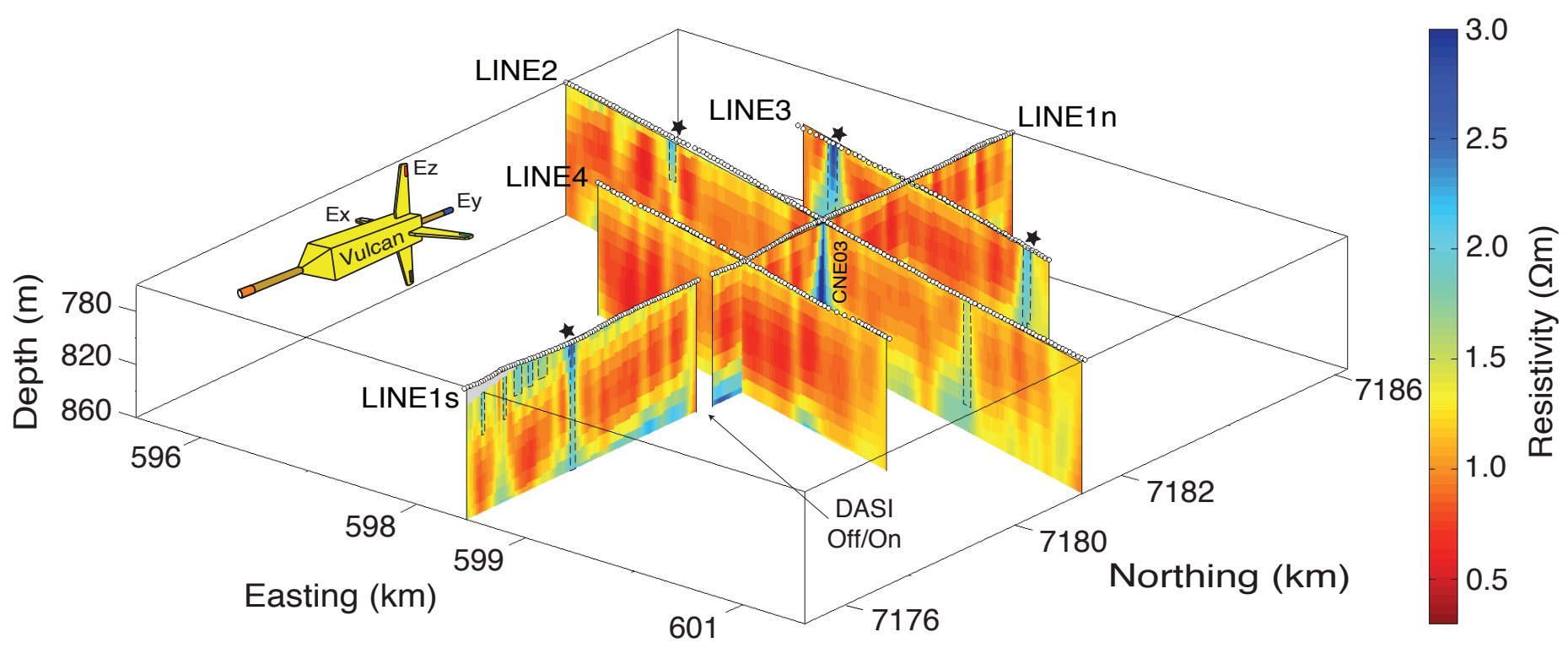

Figure 4. Fence diagram showing the Vulcan inversion models for survey lines 1-4. Areas bounded by dashed lines denote vertical resistors that were detected. The stars indicate robust resistive features $(\geqslant 2 \Omega \mathrm{m})$, presumably gas hydrate deposits. Left corner: a diagram of Vulcan — a deep-towed fixed-offset CSEM receiver. 
Towline 2 Vulcan inversion - Phase Unshifted

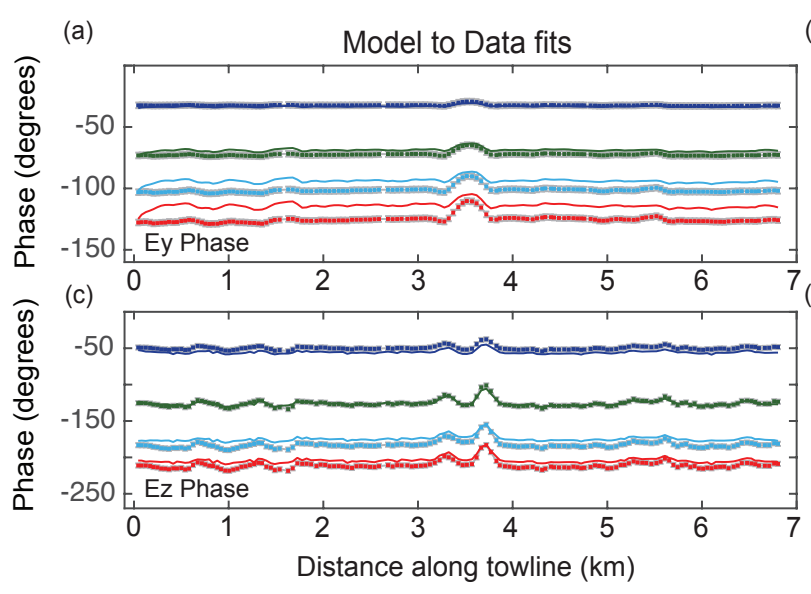

(b) Normalised Residuals

Towline 2 Vulcan inversion - Phase Shifted
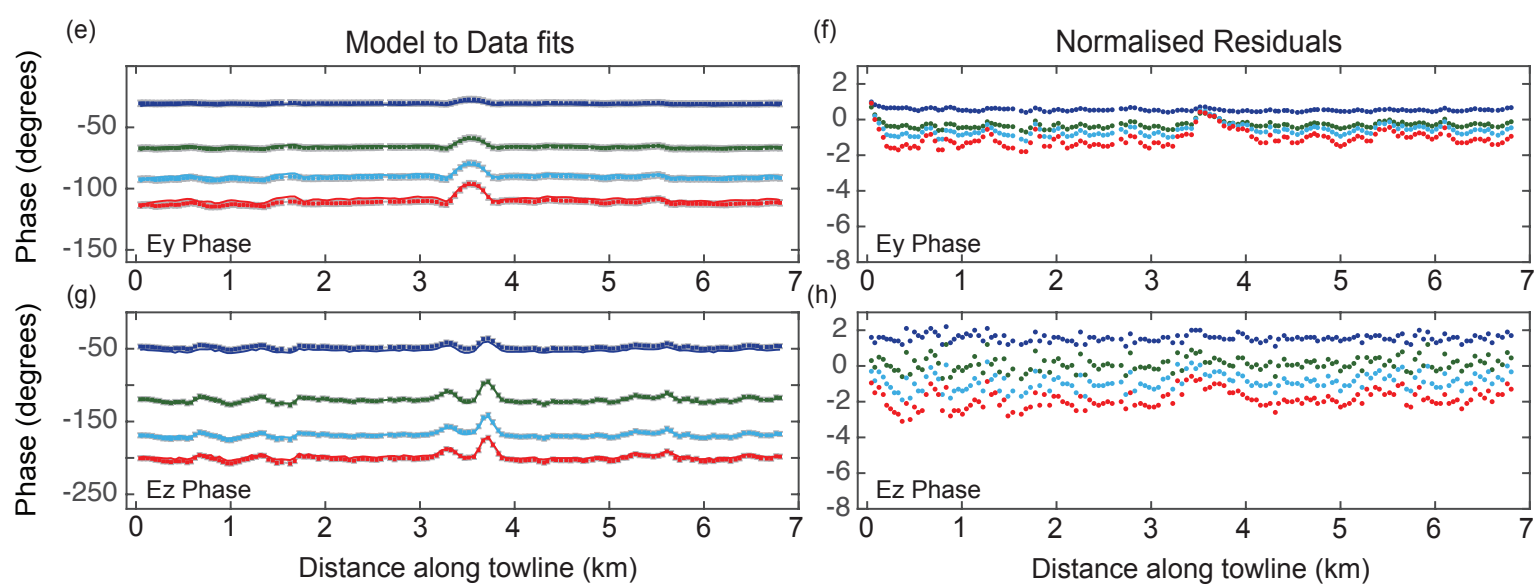

- $1 \mathrm{~Hz} \backsim \bullet 3 \mathrm{~Hz} \backsim \bullet 5 \mathrm{~Hz} \backsim \bullet 7 \mathrm{~Hz}$

Figure 5. A comparison between the responses of two Vulcan inversions: towline 2 with unshifted and shifted phase data. The inline (Ey) and Vertical (Ez) electric fields phase responses are presented, for each of the used frequencies. The lines represent the model, squares the data, error bars are in grey, and the normalised residuals are given as dots. $(\mathrm{a}-\mathrm{d})$ The model responses, data and normalised residuals responses of the inversion with unshifted phase data. This inversion could not converge to an RMS misfit below 2.1 (17 iterations). (e-h) The model responses, data and normalised residuals responses of the inversion with shifted phase data. This inversion converged to an RMS target misfit of 0.9 (6 iterations). In the unshifted phase inversion, the model does not fit the data, and the normalised residuals are $\sim 2-3$ times greater than the residuals observed in the shifted phase inversion. The elevation in phase observed between $3-4 \mathrm{~km}$ along the towline denotes the CNE03 pipe-like structure. 
30 Attias et al., (2018), manuscript for Geophys. J. Int.

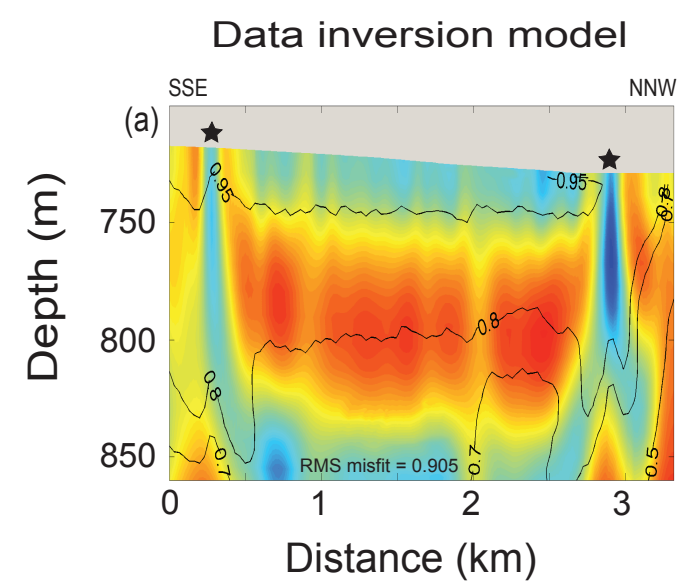

\section{Synthetic forward model}

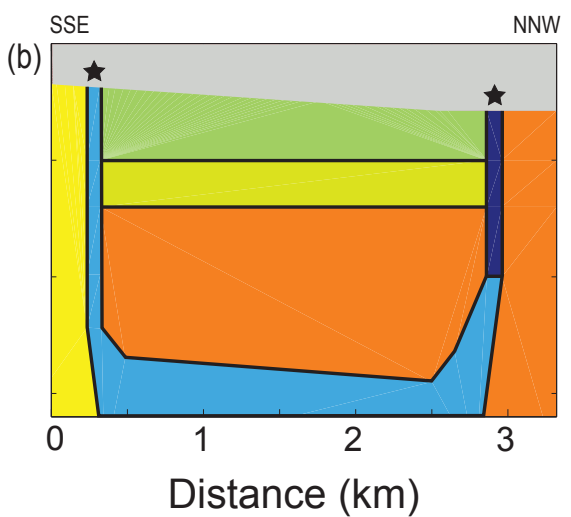

\section{Synthetic inversion model}

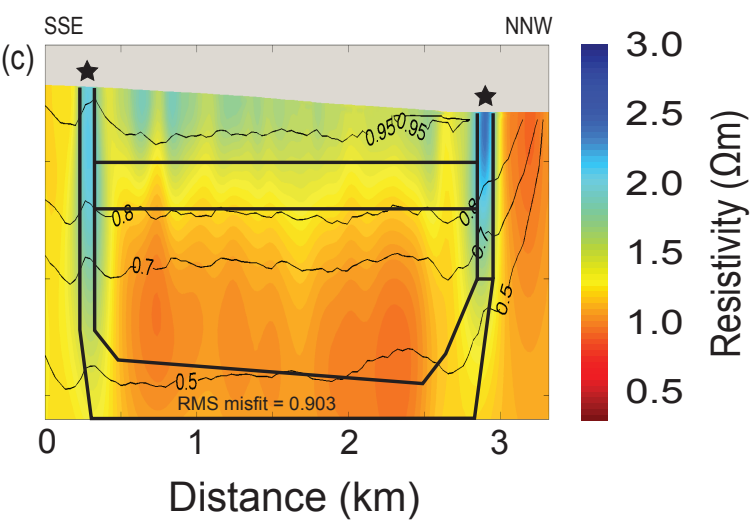

Figure 6. Vulcan towline 3: real and synthetic unconstrained inversion models. (a) Real data inversion model. (b) A synthetic forward model that includes resistive structures derived from the real data inversion. (c) Synthetic data inversion model. The stars denote newly discovered vertical resistors. The models shown in (a) and (c) are superimposed with Jacobian sensitivity contours (thin lines), which illustrates the inversion sensitivity to spatial variations in resistivity. The thick lines in (b) and (c) bound the areas with different resistivity. 

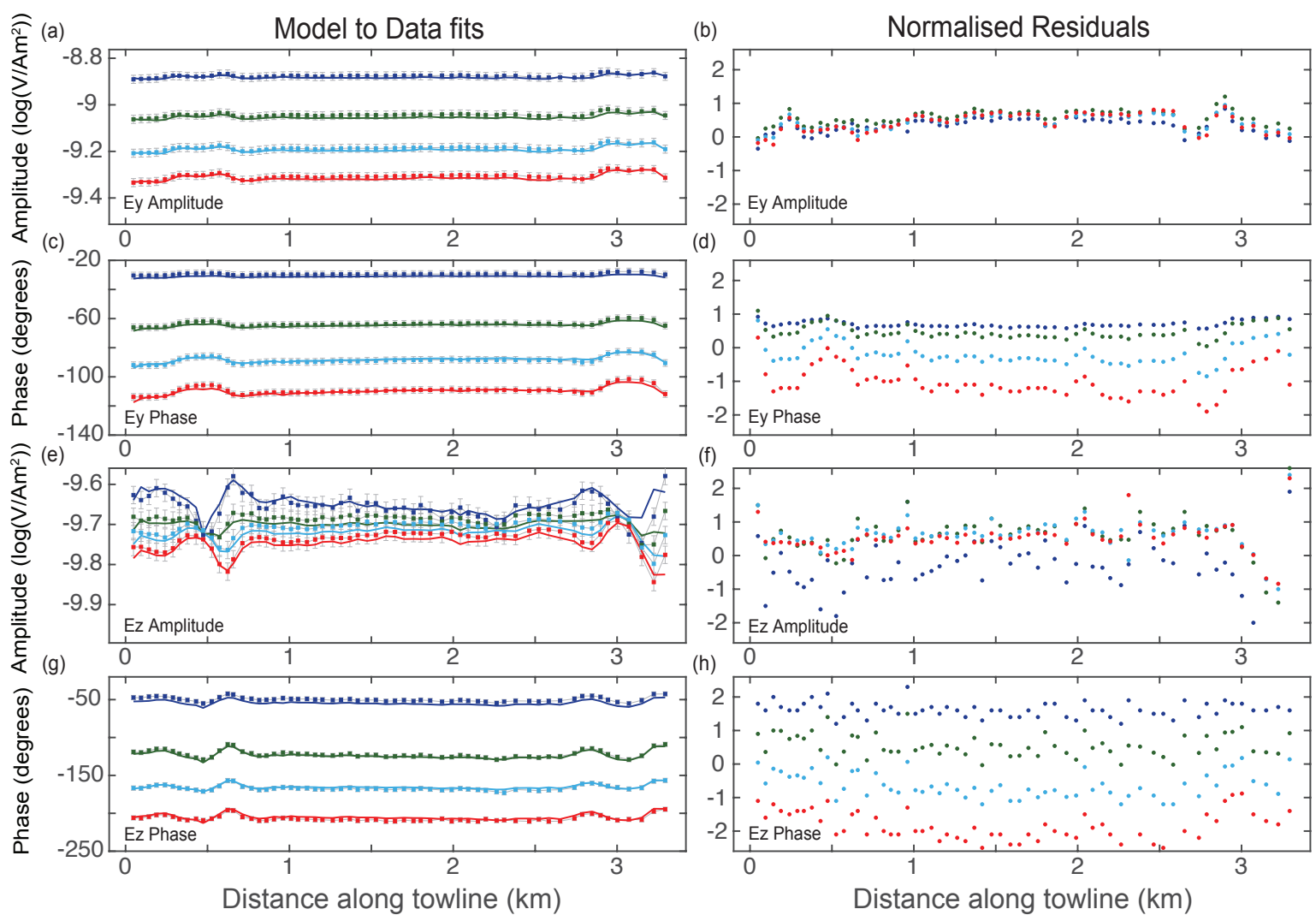

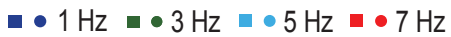

Figure 7. The model responses, data and normalised residuals of the smooth inversion applied to towline 3 Vulcan data. The inversion includes four frequencies: 1, 3, 5, and $7 \mathrm{~Hz}$. In the model to data fit plots, the vertical axes are individually scaled while the residuals are all on the same scale. The lines represent the model, squares the data and the error bars are in grey (a, c, e, g). The normalised residuals are given as dots (b, d, f, h). Two subtle resistive anomalies observed at $\sim 0.5$ and $\sim 3 \mathrm{~km}$ distance along the towline, which corresponds to the vertical resistors shown in towline 3 inversion model (Fig. 6a). These anomalous resistors (possibly gas hydrate features), subtly bias the Ey phase and Ez amplitude normalised residuals in a frequency dependent pattern. 

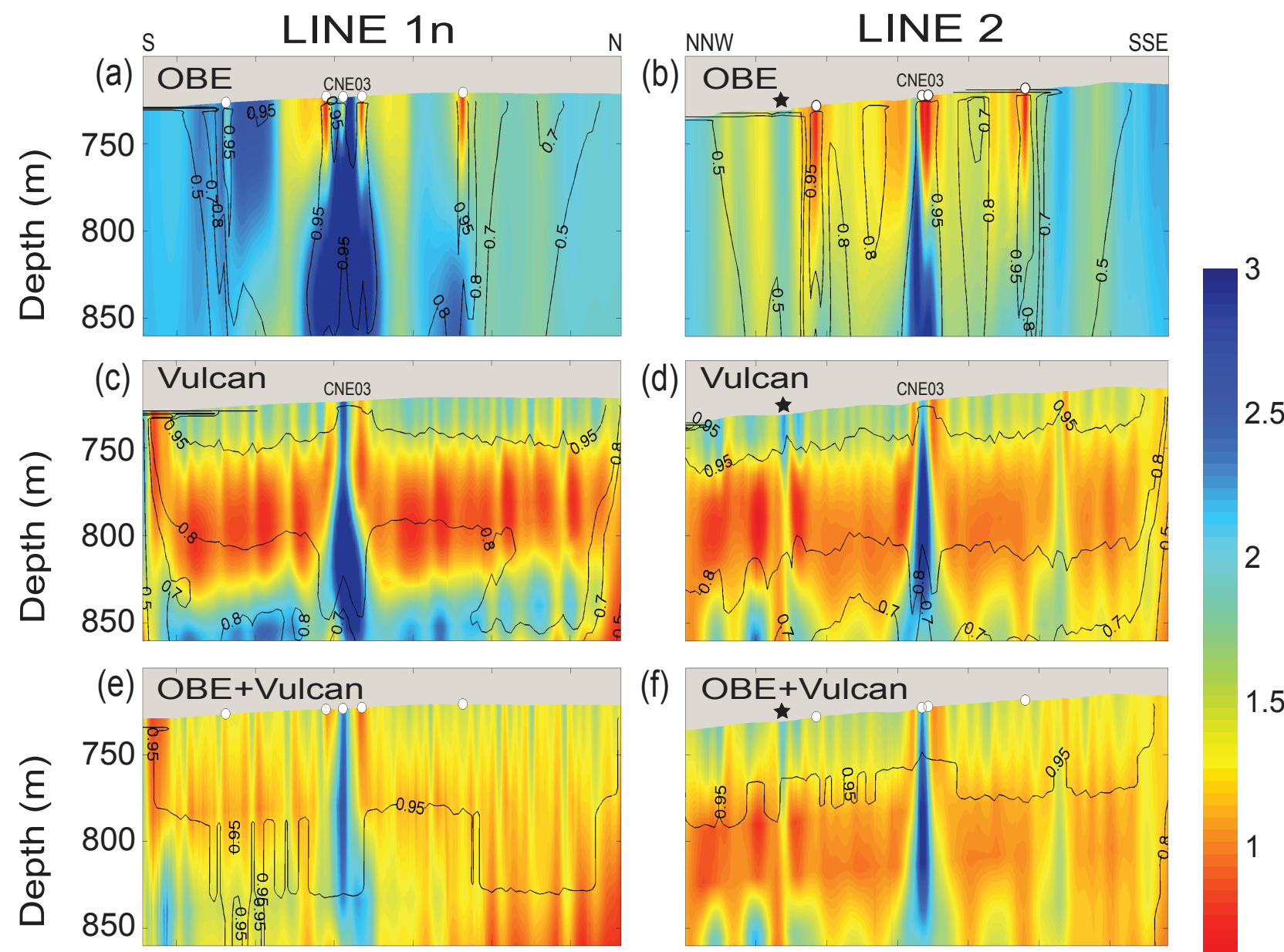

(f)
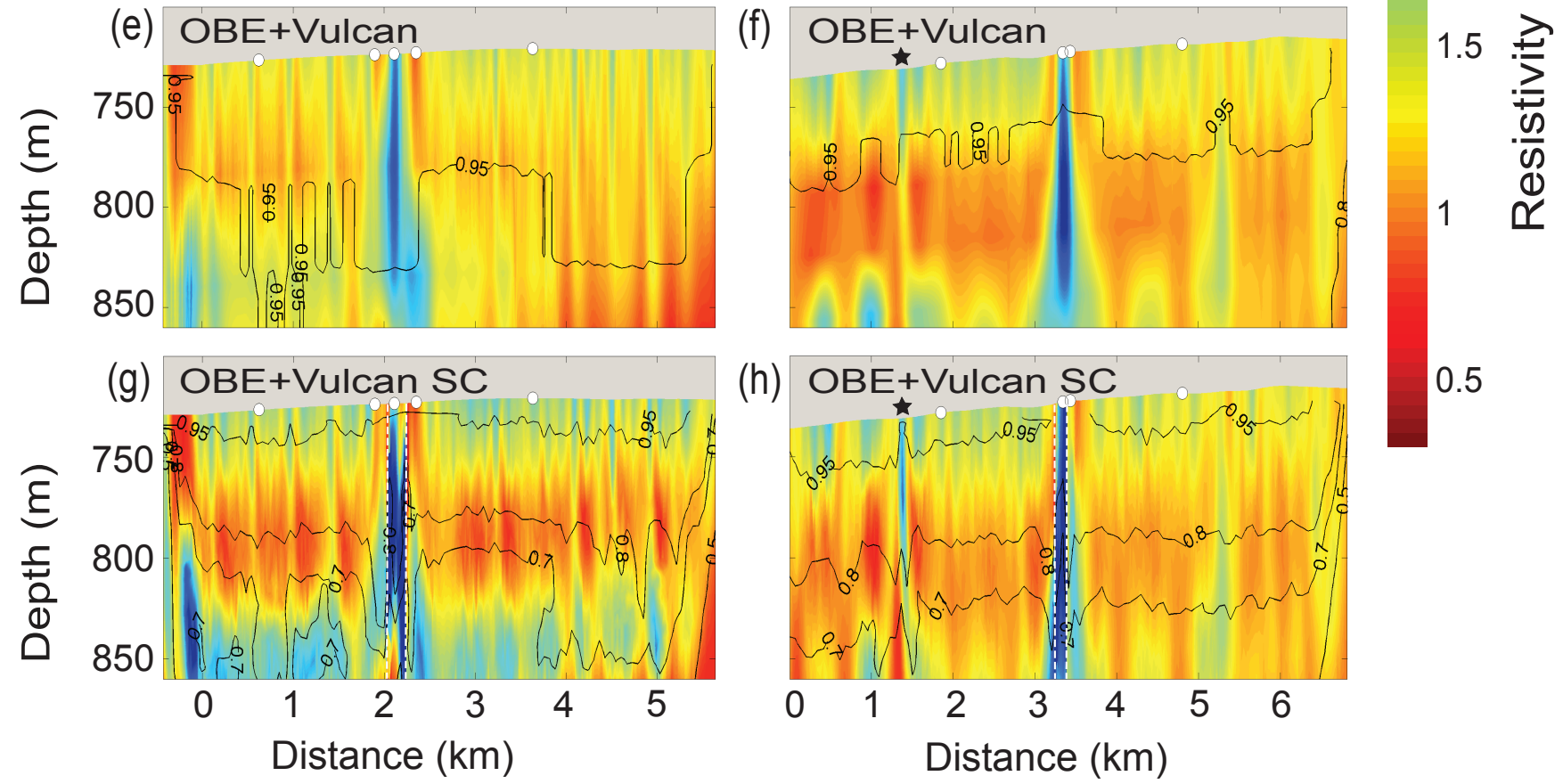

Figure 8. Inversion models of survey line 1n [(a), (c), (e), (g)] and line 2 [(b), (d), (f), (h)]: OBE and Vulcan datasets were inverted separately and simultaneously. All inversions employed a quadrilateral mesh. The sensitivity contours indicate the level of the data sensitivity to the model parameters. The circles represent the OBE positions. The stars denote a newly discovered gas hydrate structure along line 2. (g) and (h) panels: Line 1n and line 2 showing the OBE and Vulcan combined inversions, whereas the CNE03 pipe structure is seismically constrained (SC) laterally, as denoted by the bounding white dashed lines. The lateral resistivity variations (striped pattern) observed in (c)-(h) are artefacts, most likely results from the uncertainty in Vulcan geometry. The striped pattern is visually enhanced due to a vertical exaggeration of $\approx 40$ (chosen for ideal visualisation of the CNE03 anomalous structure), and the spatial horizontal to vertical $(\mathrm{H}: \mathrm{V}$ ration $=6)$ roughness regularization that we use in this study. Further details about the striped artefact pattern are given in the supporting information. 
Table 1. Properties of the OBE and Vulcan individual and combined inversion ${ }^{a}$ models presented in Figs 4, 6 and 8 .

\begin{tabular}{|c|c|c|c|c|c|c|}
\hline Line & Receiver(s) & Inversion type & Electric dipole & Data type & RMS misfit target & Iterations \\
\hline $1 \mathrm{~s}$ & Vulcan & Smooth & Ey, Ez & $\log _{(10)}$ Amplitude $^{b}$, phase $^{c}$ & 0.95 & 7 \\
\hline $1 \mathrm{n}$ & OBE & Smooth & Ey & $\log _{(10)}$ Amplitude $^{b}$, phase $^{c}$ & 0.9 & 8 \\
\hline $1 \mathrm{n}$ & Vulcan & Smooth & Ey, Ez & $\log _{(10)}$ Amplitude $^{b}$, phase $^{c}$ & 0.9 & 5 \\
\hline $1 \mathrm{n}$ & OBE+Vulcan & Smooth & $\mathrm{Ey}^{g}, \mathrm{Ez}$ & $\log _{(10)}$ Amplitude $^{b}$, phase $^{c}$ & 0.85 & 10 \\
\hline $1 \mathrm{n}$ & OBE+Vulcan & $\mathrm{SC}^{d}$ & $\mathrm{Ey}^{g}, \mathrm{Ez}$ & $\log _{(10)}$ Amplitude $^{b}$, phase $^{c}$ & 0.85 & 10 \\
\hline 2 & OBE & Smooth & Ey & $\log _{(10)}$ Amplitude $^{b}$, phase $^{c}$ & 0.9 & 5 \\
\hline 2 & Vulcan & Smooth & Ey, Ez & $\log _{(10)}$ Amplitude $^{b}$, phase $^{c}$ & 0.9 & 6 \\
\hline 2 & OBE+Vulcan & Smooth & $\mathrm{Ey}^{g}, \mathrm{Ez}$ & $\log _{(10)}$ Amplitude $^{b}$, phase $^{c}$ & 0.85 & 5 \\
\hline 2 & OBE+Vulcan & $\mathrm{SC}^{d}$ & $\mathrm{Ey}^{g}, \mathrm{Ez}$ & $\log _{(10)}$ Amplitude $^{b}$, phase $^{c}$ & 0.9 & 4 \\
\hline 3 & Vulcan & Smooth & Ey, Ez & $\log _{(10)}$ Amplitude $^{b}$, phase $^{c}$ & 0.9 & 7 \\
\hline 3 & Vulcan & Synthetic & Ey, Ez & $\log _{(10)}$ Amplitude $^{e}$, phase $^{f}$ & 0.9 & 5 \\
\hline 4 & Vulcan & Smooth & Ey, Ez & $\log _{(10)}$ Amplitude $^{b}$, phase $^{c}$ & 0.85 & 7 \\
\hline
\end{tabular}

* The RMS target misfits were achieved within a predefined tolerance of 1 per cent.

${ }^{*}$ Ey $=$ inline electric field dipole, $\mathrm{Ez}=$ vertical electric field dipole.

${ }^{*}$ OBE frequencies $=1,3,5,7,9,11 \mathrm{~Hz}$, Vulcan frequencies $=1,3,5,7 \mathrm{~Hz}$.

${ }^{*}$ Model parameters: air layer $=10^{12} \Omega \mathrm{m}$, seawater fixed parameters $=13$, sub-seafloor quadrilateral mesh free parameters $=7 \mathrm{k}-13.5 \mathrm{k}$, towline length dependent.

${ }^{a}$ General parameters: spatial horizontal to vertical $(\mathrm{H}: \mathrm{V})$ penalty weight $=6$, Lagrange multiplier $(\mu)$ starting value $=1$.

${ }^{b}$ Ey amplitude error $=4$ per cent, Ez amplitude error $=5$ per cent.

${ }^{c}$ Ey phase error $=2.29^{\circ}$, Ez phase error $=2.86^{\circ}$.

${ }^{d}$ Seismically constrained (SC), penalty cut weight $=0.1$.

${ }^{e} 4$ per cent and 5 per cent of added Gaussian noise to Ey and Ez amplitude, respectively.

$f 2.29^{\circ}$ and $2.86^{\circ}$ of added Gaussian noise to Ey and Ez phase, respectively.

${ }^{g}$ OBE: Ey only. 